\title{
Defining the Vortex Loading Period and Application to Assess Dynamic Amplification of Tornado-Like Wind Loading
}

\author{
Matthew N. Strasser ${ }^{\mathrm{a}, \mathrm{b}}$ \\ Email: mstrasse@uark.edu \\ Telephone: (870) 318-7278
}

Majdi A.A. Yousef $^{\text {a }}$

Email: myousef@email.uark.edu

$\underline{\text { R. Panneer Selvam }}^{\text {a }}$

Email: rps@uark.edu

Telephone: (615) 212-9317

${ }^{a)}$ Department of Civil Engineering, University of Arkansas, Fayetteville, Arkansas, 72701, USA. Physical Address: 4190 Bell Engineering, Fayetteville, AR 72701.

${ }^{b)}$ Corresponding author.

\begin{abstract}
Tornados are transient loading events, and several studies in the literature have shown their capability to produce dynamically amplified structure response. The present study utilizes the dynamic load factor (DLF) concept to develop the first generalized methodology to assess the
\end{abstract}


possible dynamic amplification of structure having specified fundamental period $T_{n}$ to tornadic wind loads. The two-dimensional impact of a rigid, circular cylinder by an impinging vortex is directly simulated; the resulting loading time history is then used to excite a single degree of freedom (SDOF) response model. The vortex load application period $T_{v}$ is defined as the value of $T_{n}$ for which the structure's response experiences greatest dynamic amplification. An expression for $T_{v}$ is defined as a function of three vortex properties: critical radius, translational velocity, and tangential velocity profile, so that $T_{v}$ can be computed using documented tornado-vortex properties. The range of possible tornado-vortex tangential velocity profiles is identified, and DLF curves are defined for the forcing produced by each vortex profile. A review is conducted of the range of documented tornado parameters and fundamental periods of real-world structures. Finally, the documented tornado parameters, expression for $T_{v}$, and DLF curves for the vortex profiles are used to define the possible dynamic response amplification of a structure as a function of $T_{n}$.

\section{Keywords}

- Vortex

- Dynamic Loading

- Tornado Loading

- Dynamic Load Factor

- Direct Numerical Simulation

\section{Introduction}

Tornados are transient wind loading events that produce the highest documented wind speeds on Earth. Each year, more than 1,200 tornados occur in the United States (US) and its territories (Edwards \& Brooks, 2010) causing 110 deaths (NWS, 2014) and approximately $\$ 500$ 
million US in property damage (NWS, 2012). Despite the substantial annual cost of tornados, building design codes such as ASCE 7-05 fail to make provision for tornadic wind loading.

Tornadic wind loading of a structure, illustrated in the schematic Figure 1, has been investigated using both physical experiment and computer simulation.

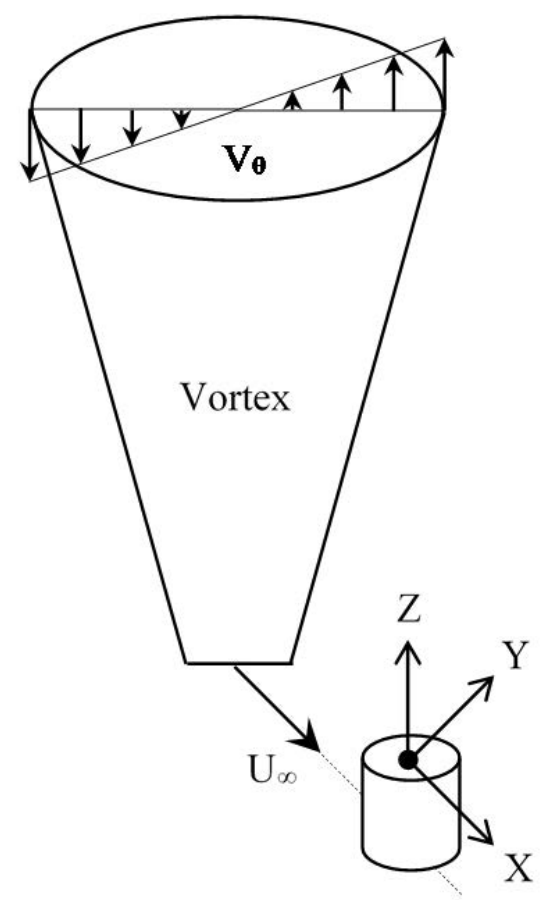

Structure

Figure 1: Loading of a structure by a tornado-like vortex.

Jischke \& Light (1983) measure forces produced on a rectangular structure by a stationary vortex and report that vortex loading is greater than loading produced by equivalent-velocity straightline wind. Selvam \& Millet (2005) simulate 3D loading of a cube by a Rankine Combined Vortex (RCVM) and report that cross-stream (Y-direction) and vertical (Z-direction) vortex loading is 1.5 and 2.0 times (respectively) greater than loading produced by simulated straightline wind. Sengupta et al. (2008) and Hann et al. (2010) use Iowa State University's translating vortex simulator to measure loading of cube and gabled-roof structures respectively by translating, tornado-like vortices. Sengupta et al. (2008) report that vortex loading on the cube is 
up to 1.5 times greater than straight-line wind loads computed via ASCE 7-05. Haan et al. (2010) report that the cross-stream and vertical loading of the gabled structure by the vortex is up to 1.5 and 3.2 times greater than straight-line wind loads computed via ASCE 7-05. Briefly summarized, tornadic winds produce cross-stream and vertical loads that are respectively 1.5 and 2.0 to 3.2 times greater than loads produced by wind having a uniform velocity distribution.

The dynamic nature of tornadic wind loading creates potential for dangerous dynamic amplification of structural response, which is commonly quantified by an integer multiple known as the dynamic load factor (DLF). Several studies evaluate the dynamic amplification of structures' responses to tornadic wind loads. All studies define the time history of the wind velocity incident on the building and then use empirical equations, which are defined as functions of the incident wind velocity, to define the forcing time history. Wen (1975) studies the response of a multi-story building to a simplified Kuo (1971) vortex and reports that the maximum structure response is amplified by DLF $=4.0$. Two similar studies evaluate multi-story structures' responses to a modified RCVM vortex and report maximum response amplification of DLF $=2.0($ Tan (1975) and Seniwongse (1977)). Dutta et al. (2002) analyze the responses of single- and multi-story structures to a tornadic wind field assigned using Fujita's (1976) wind speed record and Mehta et al.'s (1976) vortex model and report maximum structure response amplification of DLF $=1.735$.

The preceding list of studies jointly conclude that transient tornadic wind loads are capable of dynamically amplifying loaded structures' response amplitudes. Significant findings from the studies are:

1. Structure response amplitude may be amplified by DLF of 1.735 (Dutta et al., 2002) to 4.0 (Wen, 1975). 
2. Dynamic amplification of tornado wind loads is greatest when the structure is directly on the tornado's path due to the rapid change in direction and amplitude of the vortex's tangential velocity ((Wen, 1975), (Tan, 1975) and (Seniwongse, 1977)).

3. The Y-direction forcing has greatest propensity to produce amplified structure response, hence it is the forcing component that need be considered for dynamic analysis ((Tan, 1975) and (Seniwongse, 1977)).

The collective shortcoming of these studies is that they fail to yield generalized results, but rather discuss the dynamic amplification of a particular structure's response to loading by a particular wind field. Measured tornado parameters and wind field profiles, as well as real-world structure parameters, vary widely. Adequate structure design for dynamically-amplified structure response to tornadic wind loads necessitates generalized definition of the possible DLF that a specified tornadic wind field can produce in a specified structure.

DLF curves are dimensionless definitions of dynamic amplification of structure response to a specific forcing profile, hence they are an attractive option for generalizing dynamic amplification of structure response to tornadic wind loads. Generally stated, a forcing profile having amplitude $\left(\mathrm{F}_{\mathrm{o}}\right)$ and application period $\left(\mathrm{T}_{\mathrm{d}}\right)$ is applied to an un-damped $(\zeta=0)$, single degree of freedom (SDOF) structure having stiffness $(\mathrm{K})$, mass $(\mathrm{M})$ and fundamental period $\mathrm{T}_{\mathrm{n}}=$ $\left(2 \cdot \pi \cdot(\mathrm{K} / \mathrm{M})^{1 / 2}\right.$, producing maximum response $\left(\mathrm{x}_{\mathrm{m}}\right)$. Application of $\mathrm{F}_{\mathrm{o}}$ as a static load to the SDOF system would produce a displacement of $x_{s t}=F_{o} / K$; therefore, the amplification of the SDOF structure's response due to dynamic application of the forcing is DLF $=x_{m} / x_{\text {st }}$ (see additional discussion in structural dynamics texts such as Paz \& Leigh (2004) and Chopra (2005)). The SDOF structure's response is analyzed for the desired range of the ratio $T_{d} / T_{n}$ to 
define the DLF curve for the specific forcing profile as shown in Figures $2 \boldsymbol{a}$ and $2 \boldsymbol{b}$ for triangleand sine-wave forcing profiles.

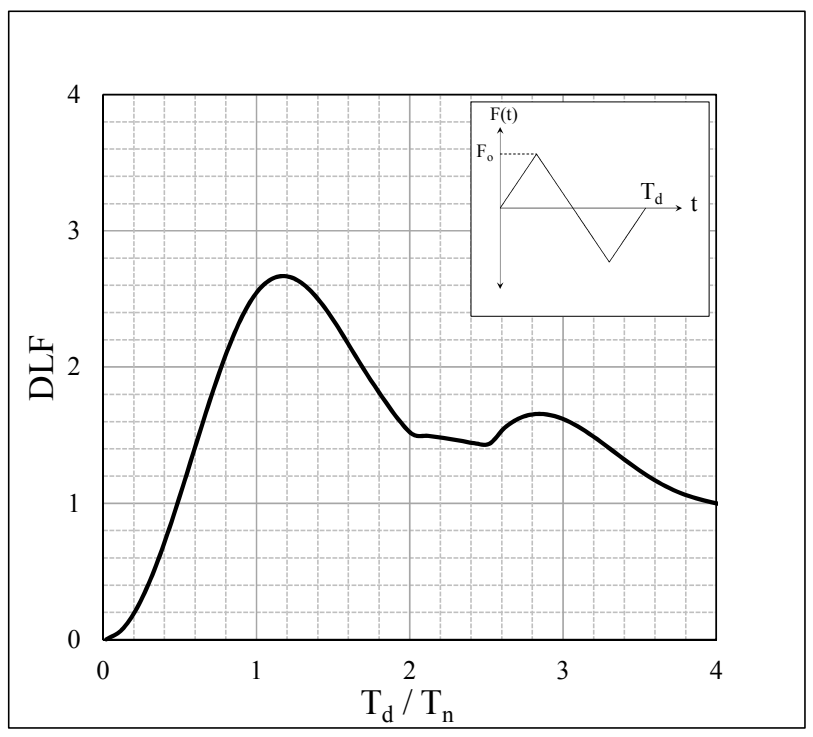

(a)

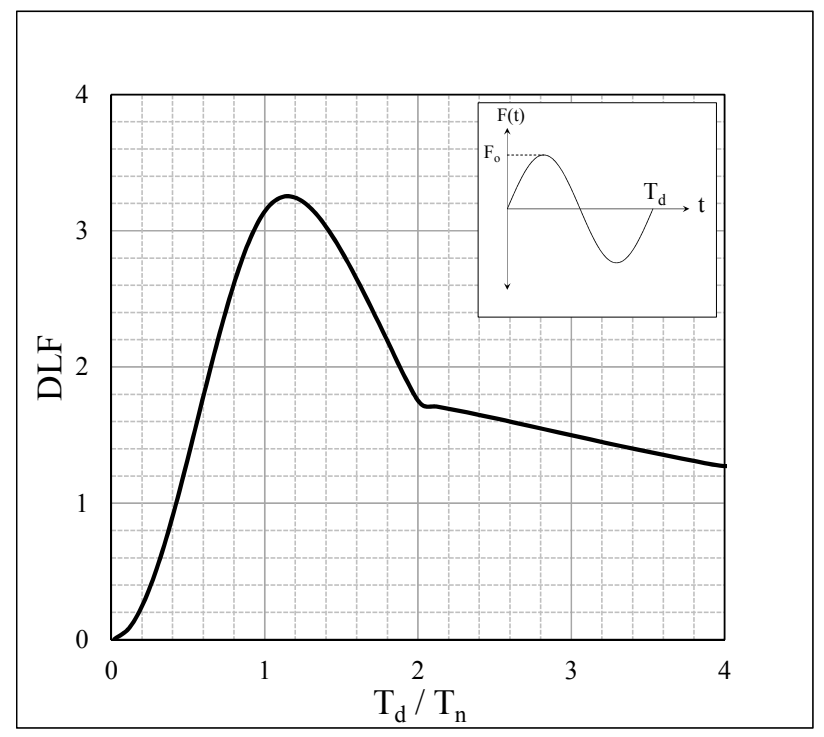

(b)

Figure 2: DLF curves for (a) triangle wave and (b) sine wave forcing profiles.

Use of DLF curves requires knowledge of only the profile of the applied forcing and the ratio $T_{d} / T_{n}$ to define the dynamic amplification of $x_{s t}$. The fundamental structure period $T_{n}$ can be computed during design or measured in existing structure; however, defining $T_{d}$ for vortex forcing presents a challenge. Unlike the periodic sine wave forcing profile (Figure 3a), the cross-stream vortex forcing profile (Figure $3 \boldsymbol{b}$ ) does not become zero at a discrete time (Note that "L-O Vortex" refers to the Lamb-Oseen vortex profile which is a specific vortex wind profile that is discussed in greater detail beginning in Section 2.1.1). Therefore, there is no intuitive definition of the vortex load application period " $T_{v}$ " $\left(T_{d}\right.$ and $T_{v}$ are analogous, but $T_{d}$ defines generic forcing while $T_{v}$ is specific to vortex forcing). Generalization of the dynamic amplification of tornado wind loading necessitates definition of $\mathrm{T}_{\mathrm{v}}$. 


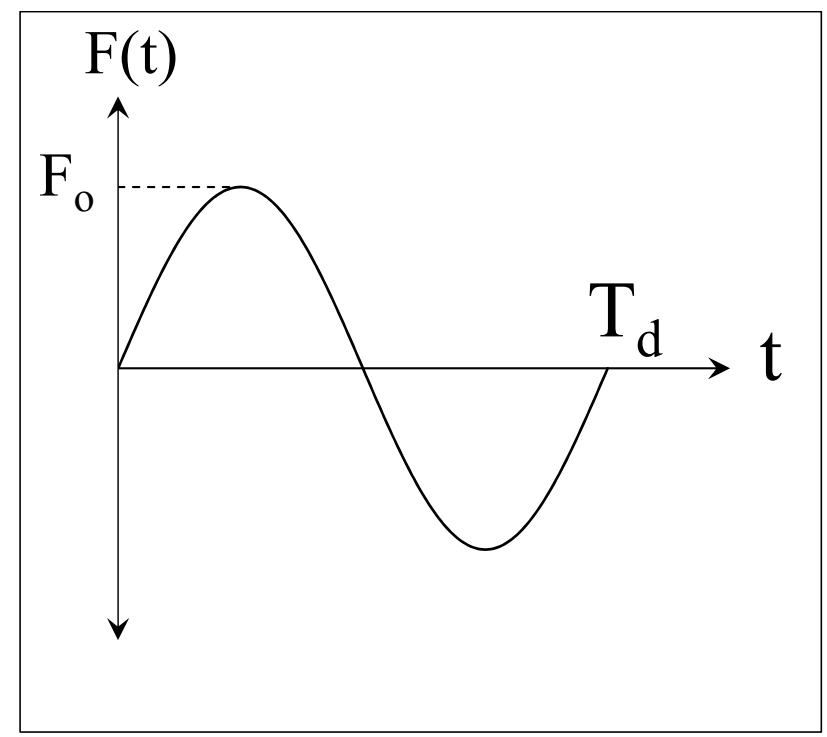

(a)

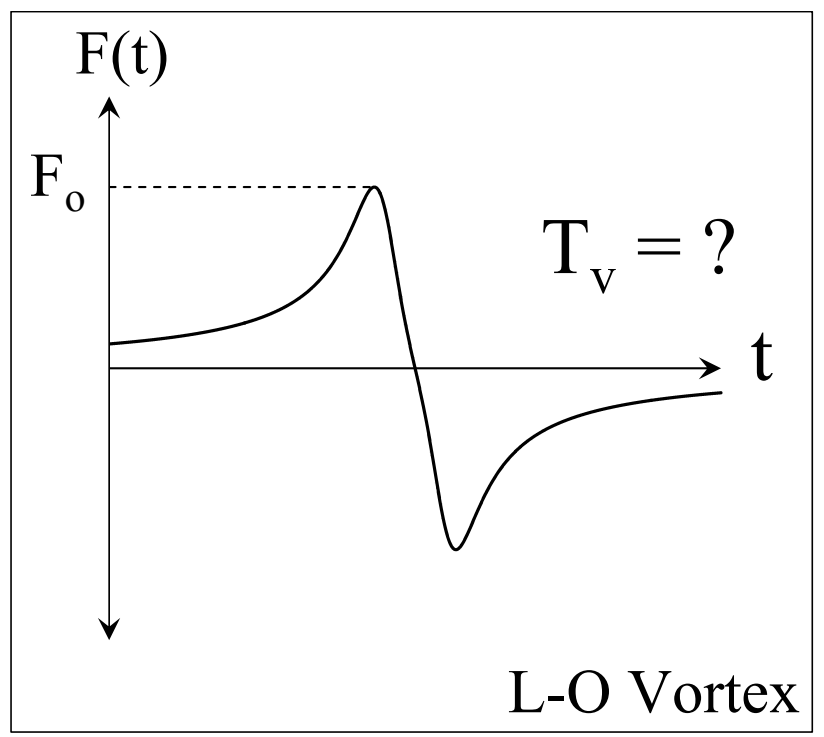

(b)

Figure 3: (a) Sine wave forcing profile having application period $T_{d}$ and (b) vortex forcing profile having unknown application period $\mathrm{T}_{\mathrm{v}}$.

The overarching goal of this study is to develop and generalize a methodology to compute the dynamic amplification of a structure's response to tornadic wind loads. The twodimensional impact of a vortex with a rigid, circular cylinder is directly simulated to produce the vortex forcing profile. Several vortex tangential velocity profiles, which represent the range of measured tornado-vortex tangential velocity profiles reported in the literature, are utilized. The cross-stream vortex forcing is applied to a SDOF response model, and DLF analysis is used to define the vortex load application period $\mathrm{T}_{\mathrm{v}}$ as a function of the vortex's parameters. Empirical equations relating the cylinder loading and the resultant velocity are then developed, validated, and used to define DLF curves for each of the considered vortex tangential velocity profiles. Finally, documented tornado-vortex parameters are surveyed and used to define the possible dynamic amplification of a structure's response to tornadic wind loading as a function of its fundamental period $\mathrm{T}_{\mathrm{n}}$. Fundamental periods of real-world structures are surveyed and classified so that the types of structures at risk for substantial dynamic response amplification are 
identified. The findings from this study constitute the first generalized approach to assess the possible dynamic amplification of structure response to tornado wind loading.

\section{Nomenclature}

A - Projected area

C - Damping coefficient

$\mathrm{Cd}$ - Drag force coefficient $\left(2 \cdot \mathrm{F}_{\mathrm{d}} / \rho \cdot \mathrm{U}_{\text {ref }}^{2} \cdot \mathrm{A}\right)$

$\mathrm{Cl}$ - Lift force coefficient $\left(2 \cdot \mathrm{F}_{1} / \rho \cdot \mathrm{U}_{\text {ref }}^{2} \cdot \mathrm{A}\right)$

$\mathrm{C}_{\mathrm{M}}$ - Mean force coefficient (Analogous to mean Cd for free stream)

$\mathrm{C}_{\mathrm{H}}-$ Harmonic force coefficient (Analogous to $\mathrm{Cl}$ amplitude for free stream)

D - Diameter of the cylinder

DLF - Dynamic amplification of structure's response to applied forcing (DLF $=\mathrm{x}_{\mathrm{m}} / \mathrm{x}_{\mathrm{st}}$ )

$F_{d}-$ Drag force

$\mathrm{F}_{1}$ - Lift force

$\mathrm{F}_{\mathrm{o}}$ - Amplitude of dynamic forcing

$\mathrm{f}_{\mathrm{Cl}}-$ Frequency of vortex shedding

$\mathrm{fn}$ - fundamental structure frequency $\left(\mathrm{f}_{\mathrm{n}}=1 / \mathrm{T}_{\mathrm{n}}\right)$

$f_{v}-$ Vortex loading frequency $\left(f_{v}=1 / T_{v}\right)$

$\mathrm{n}$ - Exponent for Vatistas' vortex model

$\mathrm{K}$ - Structure stiffness

$\mathrm{M}$ - Structure mass

$\mathrm{P}_{\infty}-$ Ambient/Reference Pressure

$\mathrm{P}^{*}$ - Dimensionless pressure $\left(\mathrm{P} / \rho \cdot \mathrm{U}_{\infty}{ }^{2}\right)$

$\mathrm{Re}-$ Reynolds number $\left(\mathrm{D} \cdot \mathrm{U}_{\infty} / v\right)$

$r$ - Radial ordinate of the vortex

$\mathrm{r}_{\mathrm{c}}-$ Critical radius for the vortex

$r_{p}{ }^{\prime}$ - Radial distance between the vortex center and the boundary node

$\mathrm{St}-$ Strouhal number, dimensionless vortex shedding frequency $\left(\mathrm{f}_{\mathrm{Cl}} \cdot \mathrm{D} / \mathrm{U}_{\infty}\right)$

$\mathrm{T}_{\text {lag }}$ - Time required for the vortex and cylinder centers to align $\left(\mathrm{X}_{\mathrm{o}} / \mathrm{U}_{\infty}\right)$

$\mathrm{T}_{\mathrm{d}}$ - Dynamic load application period

$\mathrm{T}_{\mathrm{n}}$ - Fundamental structure period 
$\mathrm{T}_{\mathrm{v}}-$ Period of vortex load

$\mathrm{T}_{\mathrm{v}}{ }^{*}-$ Dimensionless vortex loading period

$\mathrm{t}$ - Time

$\mathrm{t}^{*}$ - Dimensionless time $\left(\mathrm{t} \cdot \mathrm{U}_{\infty} / \mathrm{D}\right)$

U - Horizontal velocity

$\mathrm{U}_{\text {ref }}-$ Reference velocity

$\mathrm{U}_{\infty}$ - Bulk velocity of the fluid stream

$U^{*}-$ Dimensionless horizontal velocity $\left(\mathrm{U} / \mathrm{U}_{\infty}\right)$

$\mathrm{V}-$ Vertical velocity

$\mathrm{V}_{\mathrm{R}}-$ Resultant velocity

$\mathrm{V}_{\theta}$ - Tangential velocity of the vortex

$\mathrm{V}^{*}-$ Dimensionless vertical velocity $\left(\mathrm{V} / \mathrm{U}_{\infty}\right)$

$\mathrm{X}$ - Horizontal coordinate

$\mathrm{X}_{\mathrm{o}}$ - Starting location of the vortex

$\mathrm{X}^{*}$ - Dimensionless horizontal coordinate (X/D)

$\mathrm{X}^{\prime}$ - Horizontal ordinate of translating reference frame attached to vortex

$\mathrm{x}_{\mathrm{m}}$ - Maximum structure response to applied forcing

$\mathrm{x}_{\mathrm{p}}$ - Horizontal coordinate of boundary node with respect to cylinder center

$\mathrm{x}_{\mathrm{p}}$ '- Horizontal coordinate of boundary node with respect to vortex center

$\mathrm{x}_{\mathrm{st}}-$ Structure response to static amplification of maximum forcing value $\left(\mathrm{x}_{\mathrm{st}}=\mathrm{F}_{\mathrm{o}} / \mathrm{K}\right)$

$\mathrm{Y}-$ Vertical ordinate

$\mathrm{Y}^{*}$ - Dimensionless vertical coordinate $(\mathrm{Y} / \mathrm{D})$

$Y^{\prime}$ - Vertical ordinate of translating reference frame attached to vortex

$\mathrm{y}_{\mathrm{p}}-$ Vertical coordinate of boundary node with respect to cylinder center

$y_{p}$ ' - Vertical coordinate of boundary node with respect to vortex center

$\alpha-$ Angular velocity of the vortex

$\theta-$ Resultant velocity direction

$\delta t^{*}-$ Solution time step

$\Delta \mathrm{r}$ - Radial node spacing

$\zeta$ - Damping ratio 
$\omega_{\mathrm{n}}-$ Fundamental angular structure frequency

$\rho$ - Density of the fluid

$v$ - Kinematic viscosity of the fluid

DLF - Dynamic Load Factor

L-O - Lamb-Oseen

$\mathrm{RC}$ - Reinforced Concrete

RCVM - Rankine Combined Vortex Model

SDOF - Single Degree of Freedom

S-K - Scully-Kaufmann

\section{Computer Models}

\subsection{Problem Description and Parameters}

The vortex's tangential velocity component produces the cross-stream or forcing profile that is of concern for dynamically amplifying the structure's response. Therefore, 2D loading of a circular cylinder by a vortex (illustrated by the schematic Figure 4) is considered instead of 3D loading of a circular cylinder by a vortex which (illustrated previously in Figure 1).

Figure 4 illustrates the 2D, parallel loading of a long, rigid (or fixed), circular cylinder by a vortex. "Parallel" implies that the vortex's axis of rotation and the longitudinal cylinder axis are parallel. Generally stated, the vortex starts at initial distance $\left(\mathrm{X}_{\mathrm{o}}\right)$ to the left of the cylinder and travels at bulk velocity $\left(\mathrm{U}_{\infty}\right)$ along the cylinder's horizontal bisector. 


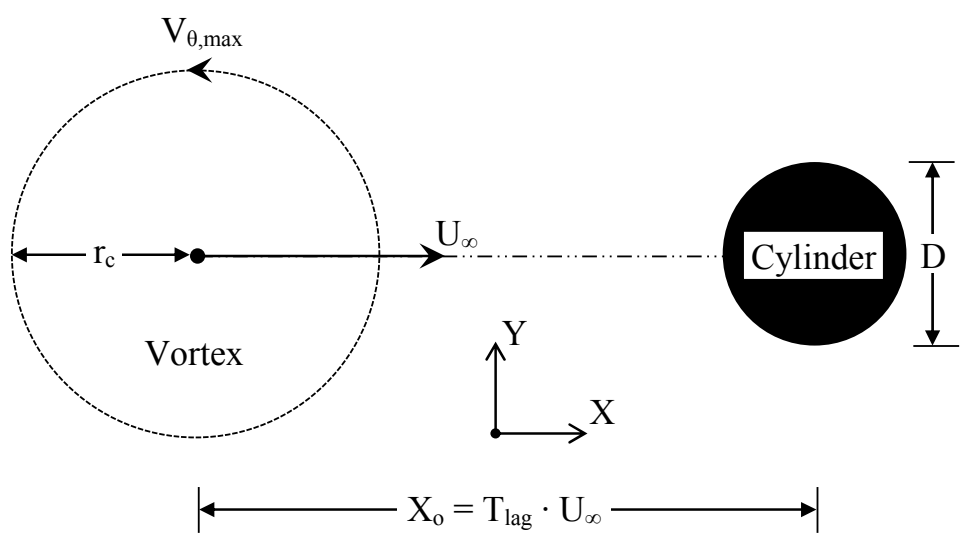

Figure 4: Schematic of the parallel loading of a rigid, circular cylinder by a vortex.

The cylinder diameter and fluid kinematic viscosity are fixed at values of $\mathrm{D}=1$ and $v=$ $150^{-1}$ respectively. The vortex's tangential velocity $\left(V_{\theta}\right)$ increases with radius $(r)$ from the vortex center, reaching a fixed maximum value $\left(\mathrm{V}_{\theta, \max }\right)$ at the critical radius $\left(\mathrm{r}_{\mathrm{c}}\right)$ and then diminishing for $r>r_{c}$. Maximum tangential velocity $V_{\theta, \max }$ is the product of $r_{c}$ and the angular velocity $(\alpha)$ and is equal to unity for all simulations $\left(\mathrm{V}_{\theta, \max }=\mathrm{r}_{\mathrm{c}} \cdot \alpha=1\right) . \mathrm{V}_{\theta, \max }=1.0$ implies that the magnitude of $\alpha$ is $r_{c}^{-1}$, meaning that the vortex's rotation rate progressively slows as it becomes larger. The critical radius of the impinging vortex ranges from $2 \leq r_{c} / D \leq 10$. The vortex's translational velocity is $\mathrm{U}_{\infty}=1.0$ in all cases except in Section 4.3 where $1.0 \leq \mathrm{U}_{\infty} \leq 2.0$, meaning that the free stream Reynolds number (Re) varies from 150 to 300 .

X-direction "drag" $\left(\mathrm{F}_{\mathrm{d}}\right)$ and Y-direction "lift" $\left(\mathrm{F}_{1}\right)$ forces on the cylinder are computed by integrating the surface pressure and shear. The forces are then re-dimensioned to the typicallydiscussed drag $\mathrm{Cd}=2 \cdot \mathrm{F}_{\mathrm{d}} / \rho \cdot \mathrm{A} \cdot \mathrm{U}_{\text {ref }}{ }^{2}$ and lift $\mathrm{Cl}=2 \cdot \mathrm{F}_{1} / \rho \cdot \mathrm{A} \cdot \mathrm{U}_{\text {ref }}{ }^{2}$ force coefficients, where $\rho=1.0$, $A=1.0$, and $U_{\text {ref }}=2.0$ are the fluid density, projected area of the cylinder per unit length, and reference velocity. Finally, the time lag $\left(\mathrm{T}_{\mathrm{lag}}\right)$ is specified such that the centers of the vortex and the cylinder coincide when dimensionless time $\left(\mathrm{t}^{*}\right)$ is zero. This is illustrated in Figure 4 by fixing the starting location of the vortex $\left(\mathrm{X}_{\mathrm{o}}\right)$. 


\subsubsection{Explanation for Usage of a Low Reynolds Number}

The simulations reported in this are at low Reynolds numbers $(\operatorname{Re}<300)$ compared with typical characterizing Reynolds numbers for vortex-structure interaction $\left(\operatorname{Re}>10^{7}\right)$. The twodimensional physical system modeled herein restricts the simulation to low Reynolds numbers $(\operatorname{Re}<300)$ because Williamson's (1996) experiments show that flow in this system gains threedimensional features at higher Reynolds numbers. Furthermore, the present study is a direct simulation, so extensive grid resolution (And accompanying computational expense) is required to extend to higher Reynolds numbers.

The primary benefit of the system modeled herein is that computational time is reduced. Therefore, the influence of numerous vortex parameters on the dynamic amplification of the vortex-induced loading can be evaluated. Subsequently, more detailed and rigorous threedimensional modeling can be used to extend these studies the higher Reynolds numbers once the theory is in place and areas of study requiring further resolution have been identified.

\subsection{Governing Equations}

The CFD simulation is governed by incompressible continuity Eq. (1) and conservation of momentum Eq. (2). The governing equations are written in tensor notation where subscript "i" is the index, " $i$ " and " $\mathrm{j}$ " are 1 for " $\mathrm{x}$ " and 2 for " $y$ ", subscript " $t$ " is time, and a comma implies differentiation with respect to the variable indicated by the subsequent subscript.

$$
\begin{gathered}
\mathrm{U}_{\mathrm{i}, \mathrm{i}}^{*}=0 \\
\mathrm{U}_{\mathrm{i}, \mathrm{t}}^{*}+\mathrm{U}_{\mathrm{j}}^{*} \mathrm{U}_{\mathrm{i}, \mathrm{j}}^{*}+\mathrm{P}_{, \mathrm{i}}^{*}+\mathrm{Re}^{-1}\left[\mathrm{U}_{\mathrm{i}, \mathrm{j}}^{*}+\mathrm{U}_{\mathrm{j}, \mathrm{i}}^{*}\right]_{, \mathrm{j}}=0
\end{gathered}
$$

Selvam (1998) reviews numerous treatments of the non-linear convection term and identifies the balance tensor diffusion scheme (Dukowicz \& Ramshaw, 1979) as the most accurate. Specifically, “ $-\delta t^{*} / 2\left(U_{j}{ }^{*} U_{k}{ }^{*} U_{i, j}{ }^{*}\right), k$ " is added to $U_{j}{ }^{*} U_{i, j}{ }^{*}$, where $\delta t^{*}$ is the solution time 
step. Selvam (1997a) provides additional details outlining the implementation of the balance tensor diffusion scheme.

\subsubsection{Vortex Wind Field Model}

Realistic simulation of vortex loading of structures necessitates the use of a realistic vortex tangential velocity profile. Bhagwat \& Leishman (2002) and Wood \& White (2011) provide detailed reviews of analytical vortex tangential velocity profiles used in the aerospace and meteorological communities respectively. Both studies identify Vatistas' (1991) profile as a realistic representation of measured vortex profiles; it is particularly attractive for integration into a computer model because varying the exponent " $n$ " replicates the commonly-used profiles summarized in Table 1. The authors' previous work (Strasser \& Selvam, 2015) defines Eq. (3), which is a normalized version Vatistas' original profile where $V_{\theta, \max }=\alpha \cdot r_{c}$ for all values of $n$.

$$
\mathrm{V}_{\theta}(\mathrm{r})=\alpha \cdot \mathrm{r} \cdot\left[\frac{2}{\left(\mathrm{r} / \mathrm{r}_{\mathrm{c}}\right)^{2 \mathrm{n}}+1}\right]^{1 / \mathrm{n}}
$$

Table 1: Analytical vortex tangential velocity profiles approximated using Eq. (3).

\begin{tabular}{|c|c|c|}
\hline Profile & Abbreviation & $\mathrm{n}$ \\
\hline Rankine Combined & RCVM & 100 \\
\hline Lamb-Oseen & L-O & 2 \\
\hline Scully-Kauffman & S-K & 1 \\
\hline
\end{tabular}

The present study seeks to utilize a vortex tangential velocity profile that replicates a tornado. Figure 5a summarizes dimensionless tornado-vortex tangential velocity profiles measured via in-field Doppler radar. The profiles are qualitatively similar, yet they vary quantitatively; therefore, no single profile can be used to define all tornado vortices. Figure $4 \boldsymbol{b}$ compares the three analytical vortex profiles defined in Table 1 with the measured vortex profiles. The S-K and RCVM profiles are effective upper and lower bounds to the measured vortex profiles. The L-O profile bisects the measured profiles, hence it represents the "typical" 
vortex profile and will be used unless otherwise stated. However, S-K and RCVM profiles will be used later when the influence of the vortex profile on $T_{v}$ is evaluated.

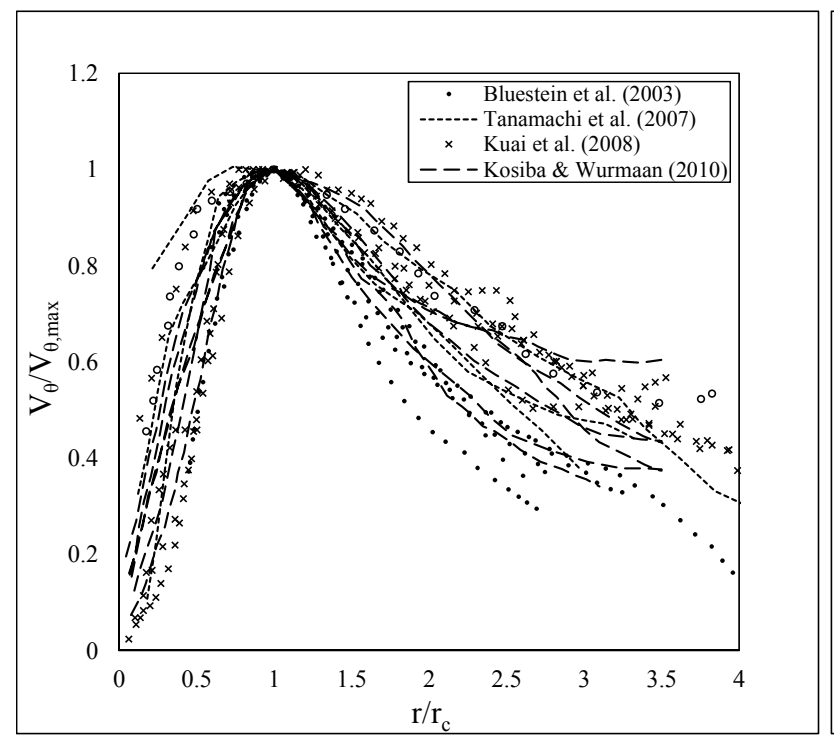

(a)

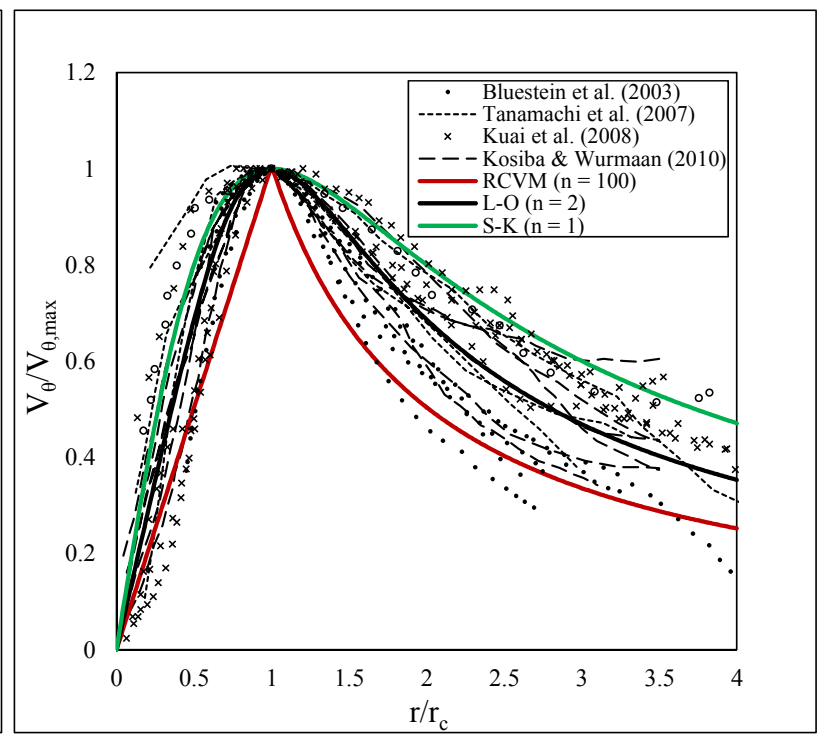

(b)

Figure 5: (a) Dimensionless, tornado-vortex tangential velocity profiles and (b) comparison with analytical tangential velocity profiles defined by Eq. (3).

\subsection{Numerical Method}

The present model is a finite element adaption of the node-centered, non-staggered control volume procedure introduced in Selvam (1997a). The Backward Euler time advancement scheme is incorporated. Solution of the pressure and velocity field at each time step follows the four step advancement procedure outlined below, where steps 1 and 3 incorporate preconditioned conjugate gradient solvers.

1. Solve $\mathrm{U}_{\mathrm{i}}^{*}$ from Eq. (2).

2. Update velocity field: $\mathrm{U}_{\mathrm{i}}^{* *}=\mathrm{U}_{\mathrm{i}}^{*}+\delta \mathrm{t}^{*} \cdot \mathrm{P}_{, \mathrm{i}}{ }^{*}$

3. Solve for pressure field: $\left(\mathrm{P}_{\mathrm{i}}^{*}\right)_{\mathrm{i}} \mathrm{i}=\mathrm{U}_{\mathrm{i}, \mathrm{i}}^{* *} / \delta \mathrm{t}^{*}$

4. Correct velocity for incompressibility: $\mathrm{U}_{\mathrm{i}}^{*}=\mathrm{U}_{\mathrm{i}}^{* *}-\delta \mathrm{t}^{*} \cdot \mathrm{P}_{\mathrm{i}}^{*}$

The checkerboard pressure field is eliminated using equal-order interpolation of the pressure and velocity terms, along with step 2 . The higher order portion of the convection term and the diffusion term are treated implicitly, removing the time step restriction for numerical stability. A 
constant time step of $\delta \mathrm{t}^{*}=0.01$ is used for all simulations so that the Courant-Friedrichs-Lewy (CFL) number is always less than one. At each time step, steps 1-4 are iterated until the average residual at each node falls below $10^{-7}$. Selvam (1997b) provides further details of the finite element methodology and solution algorithm.

\subsection{Domain and Boundary Conditions}

Figures $6 \boldsymbol{a}$ and $\mathbf{6 b}$ illustrate the computational domain and grid respectively. Upstream and spanwise boundaries are $15 \cdot \mathrm{D}$ from the cylinder's center, and the downstream boundary is $50 \cdot \mathrm{D}$ from the cylinder's center. The cylinder's surface is defined by 120 nodes spaced at $3^{\circ}$ increment around its circumference. The first radial node is spaced $\Delta \mathrm{r}_{1}=0.0075 \cdot \mathrm{D}$ from the cylinder surface, and subsequent radial spacing is defined $\Delta \mathrm{r}_{\mathrm{i}}=1.10 \cdot \Delta \mathrm{r}_{\mathrm{i}-1}$ up to a maximum of $0.5 \cdot \mathrm{D}$. Beyond this point, constant radial node spacing of $0.5 \cdot \mathrm{D}$ is used.

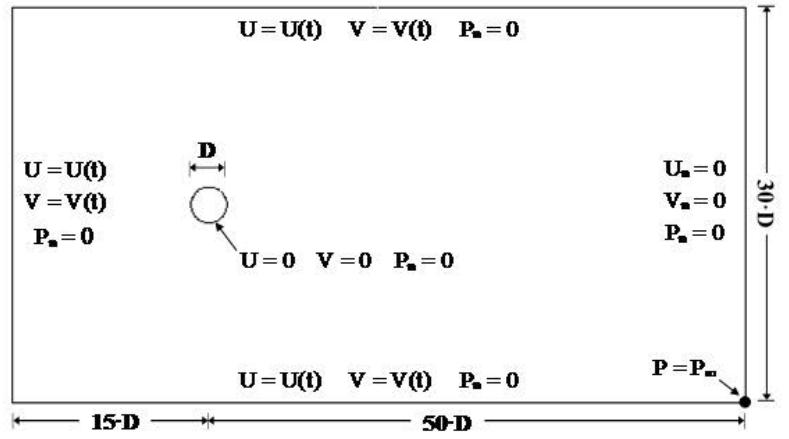

(a)

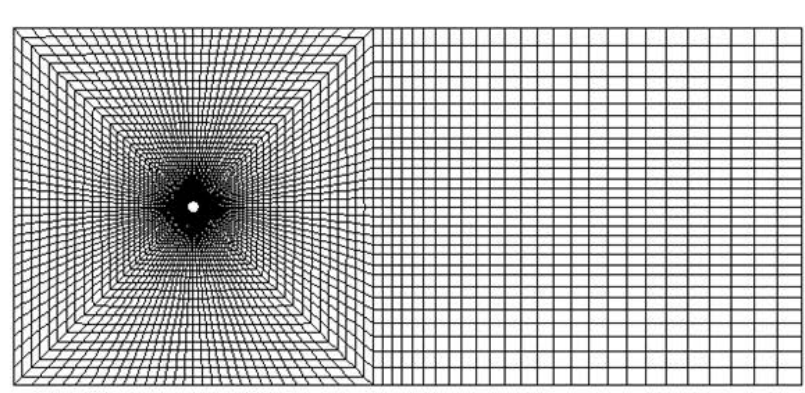

(b)

Figure 6: Schematics of the (a) computational domain and (b) grid.

Boundary conditions are illustrated along each surface of Figure 6a, with subscript " $n$ " implying differentiation with respect to the normal direction. The downstream boundary is far from the cylinder, hence the normal derivative of velocity is zero. The no slip condition is applied at the cylinder's surface. Pressure is specified to the ambient value in the lower-right corner of the domain, which is required for the numerical solution procedure. The normal derivative of pressure is zero along the cylinder surface and around the edge of the domain. 
Finally the velocity at the upstream and span-wise boundaries is specified as a transient boundary condition which is computed at each boundary node at each time step based upon the local resultant velocity from superposition of $\mathrm{U}_{\infty}$ and $\mathrm{V}_{\theta}$.

\subsubsection{Transient Velocity Boundary Condition}

Figure 7 illustrates the parameters used to compute the transient velocity boundary condition applied at the upstream and lateral boundaries. The XY coordinate system originates at the cylinder's center and is fixed. The X'Y' coordinate system originates at the vortex's center and translates with the vortex. The XY and X'Y' coordinate systems are linked by the requirement that the $\mathrm{Y}$ and $\mathrm{Y}^{\prime}$ axis align when $\mathrm{t}^{*}=0$.

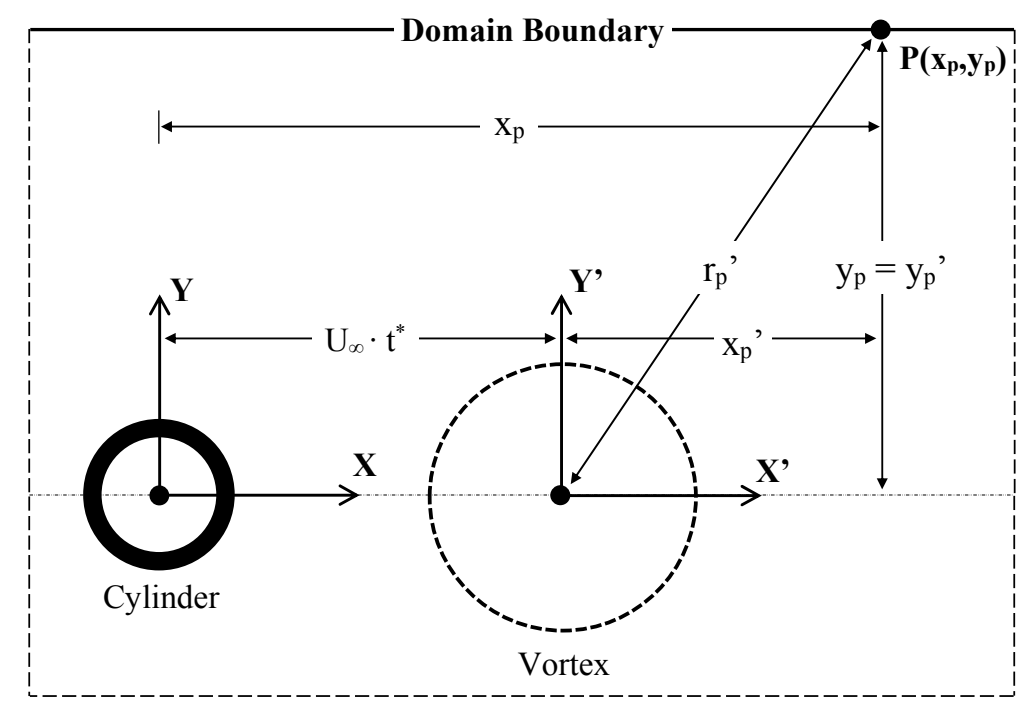

Figure 7: Vortex-cylinder schematic used to develop the transient velocity boundary condition.

The coordinates of each boundary node $(\mathrm{P})$ are fixed $\left(\mathrm{x}_{\mathrm{p}}, \mathrm{y}_{\mathrm{p}}\right)$ with respect to the cylinder center. The relative position of each boundary node to the vortex center $\left(x_{p}{ }^{\prime}, y_{p}{ }^{\prime}\right)$ is computed at each time step using Eqs. (4a-4b). The radial distance between the vortex center and the boundary node $\left(\mathrm{r}_{\mathrm{p}}{ }^{\prime}\right)$ is then computed using Eq. (5).

$$
\begin{gathered}
\mathrm{x}_{\mathrm{p}}{ }^{\prime}=\mathrm{x}_{\mathrm{p}}-\mathrm{U}_{\infty} \cdot \mathrm{t}^{*} \\
\mathrm{y}_{\mathrm{p}}^{\prime}=\mathrm{y}_{\mathrm{p}}
\end{gathered}
$$




$$
r_{p}^{\prime}=\left(x_{p}^{\prime 2}+y_{p}^{\prime 2}\right)^{1 / 2}
$$

Now $\mathrm{V}_{\theta}\left(\mathrm{r}_{\mathrm{p}}{ }^{\prime}\right)$ is computed using Eq. (3). Finally, Eqs. (6a-6b) are used to transform the tangential velocity into horizontal and vertical components and add them to the bulk velocity of the free stream " $\mathrm{U}_{\infty}$ ", thereby defining the transient velocity boundary condition at each node.

$$
\begin{gathered}
\mathrm{U}(\mathrm{t})=\mathrm{U}_{\infty}-\mathrm{V}_{\theta}\left(\mathrm{r}_{\mathrm{p}}{ }^{\prime}\right) \cdot \mathrm{y}_{\mathrm{p}}{ }^{\prime} / \mathrm{r}_{\mathrm{p}}{ }^{\prime} \\
\mathrm{V}(\mathrm{t})=\mathrm{V}_{\theta}\left(\mathrm{r}_{\mathrm{p}}{ }^{\prime}\right) \cdot \mathrm{x}_{\mathrm{p}}{ }^{\prime} / \mathrm{r}_{\mathrm{p}}{ }^{\prime}
\end{gathered}
$$

Eqs. (6a-6b) are valid for any node within the domain and are used to initialized the domain's velocity field at the onset of the simulation.

\subsection{Numerical Validation}

The first stage of model validation is to simulate free stream flow over the cylinder and assess the capability of the grid and model to resolve the boundary layer around the cylinder. Four Re values that are commonly-used benchmarks in the literature are utilized. Table 2 compiles mean $\mathrm{Cd}$ values and Strouhal numbers ( $\mathrm{St}$ ) from the present study and compares them with values reported by other numerical simulations in the literature. The present values of $\mathrm{Cd}$ and St agree with the literature to within $1.75 \%$ and $1.50 \%$ respectively, which are acceptable error bounds for the present study.

Table 2: Comparison of mean $\mathrm{Cd}$ and $\mathrm{St}$ attained in the present study with values reported by other computer simulation studies in the literature.

\begin{tabular}{|c|cc|cc|cc|}
\hline \multirow{2}{*}{$\mathrm{Re}$} & \multicolumn{2}{|c|}{ (Mittal, 2005) } & \multicolumn{2}{|c|}{ (Qu et al., 2013) } & \multicolumn{2}{c|}{ (Current) } \\
& $\mathrm{Cd}$ & $\mathrm{St}$ & $\mathrm{Cd}$ & $\mathrm{St}$ & $\mathrm{Cd}$ & $\mathrm{St}$ \\
\hline 100 & 1.322 & 0.1644 & 1.317 & 0.1649 & 1.332 & 0.1641 \\
150 & $\sim \sim \sim$ & $\sim \sim \sim$ & 1.301 & 0.1841 & 1.312 & 0.1817 \\
200 & 1.327 & 0.1947 & 1.316 & 0.1958 & 1.317 & 0.1930 \\
300 & 1.370 & 0.2077 & $\sim \sim \sim$ & $\sim \sim \sim$ & 1.346 & 0.2061 \\
\hline
\end{tabular}


The second stage of model validation is assessing the model and grid's capability to transport the impinging vortex across the domain to impact the cylinder. Both Selvam (1998) and Tamura et al. (2008) cite the challenge of convectively transporting a vortex due to numerical diffusion (Recall that the convection term is nonlinear and difficult to accurately approximate numerically). It is therefore necessary to quantify numerical diffusion of the vortex as it is transported across the domain so that informed conclusions may be drawn regarding the resulting cylinder loading.

The validation study is performed using two vortex sizes, $r_{c}=2 \cdot D$ and $3 \cdot D$, and the model's capability to transport each of the three profiles defined in Table $\mathbf{1}$ is assessed for each vortex size. Vortex transport accuracy is assessed by extracting the impinging vortex's tangential velocity profiles at discrete intervals as it traverses the domain, which are then compared with analytical profiles defined by Eq. (3). Figures $8 \boldsymbol{a}$ and $\mathbf{8 c}$ respectively illustrate the profiles defined by Eq. (3) and extracted from simulations for the $r_{c}=2 \cdot D$ study, and Figures $8 \boldsymbol{b}$ and $8 \boldsymbol{d}$ respectively illustrate the same profiles for the $r_{c}=3 \cdot D$ study. Table 3 summarizes the percentage of $\mathrm{V}_{\theta, \max }$ transported to the point of impact with the cylinder for each vortex size and profile.

Table 3: Percentage of $V_{\theta, \max }$ transported for each vortex size and profile.

\begin{tabular}{|c|c|c|c|}
\hline \multirow{2}{*}{$r_{c}$} & \multicolumn{3}{|c|}{ Profile } \\
\cline { 2 - 4 } & RCVM & L-O & S-K \\
\hline $2 \cdot \mathrm{D}$ & $80 \%$ & $94 \%$ & $98 \%$ \\
$3 \cdot \mathrm{D}$ & $91 \%$ & $>99 \%$ & $>99 \%$ \\
\hline
\end{tabular}




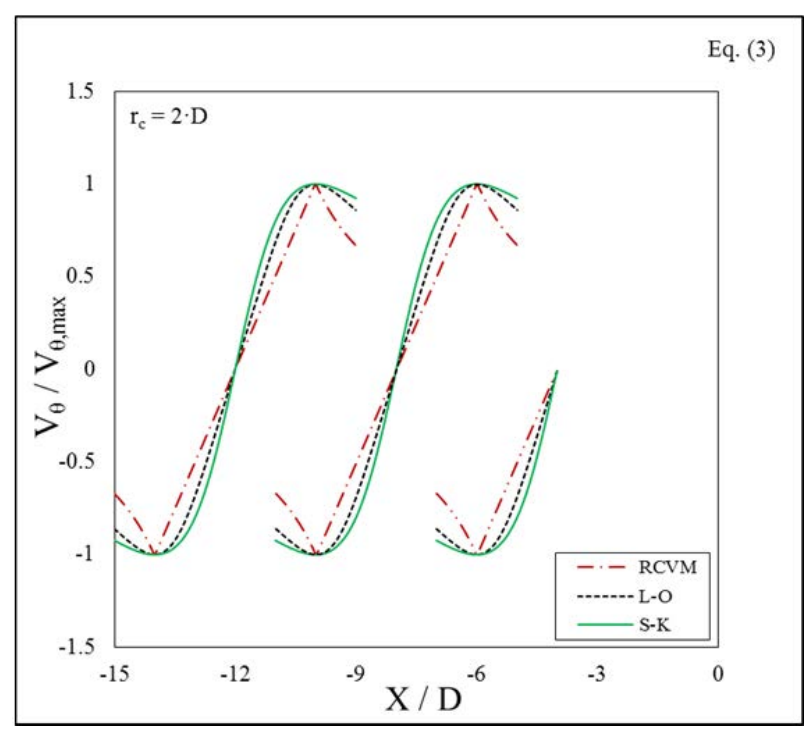

(a)

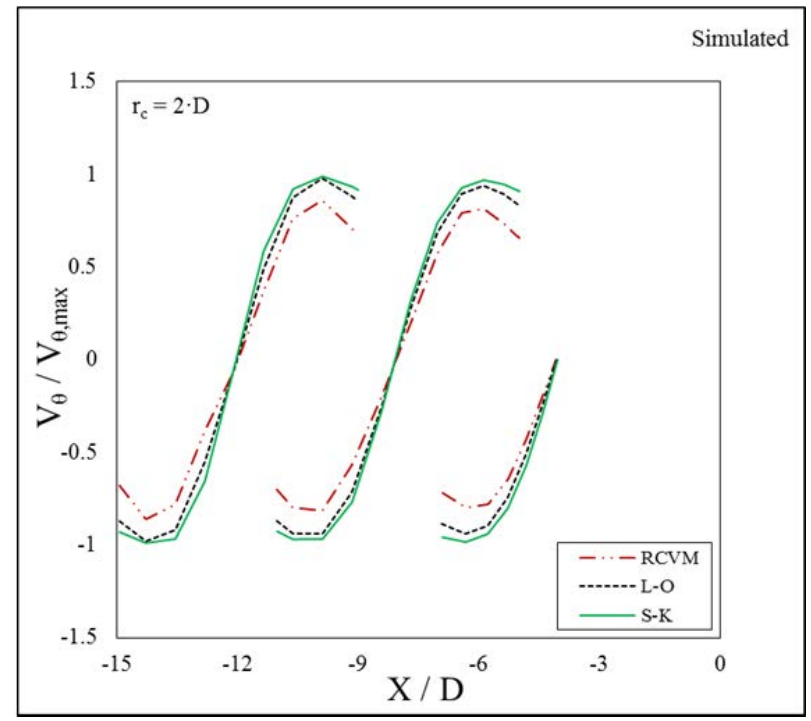

(c)

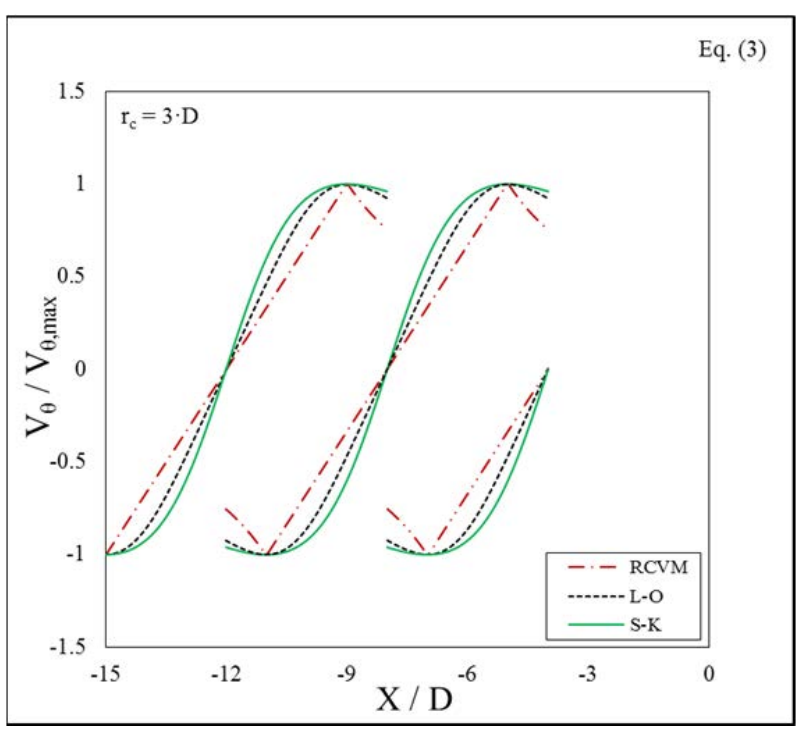

(b)

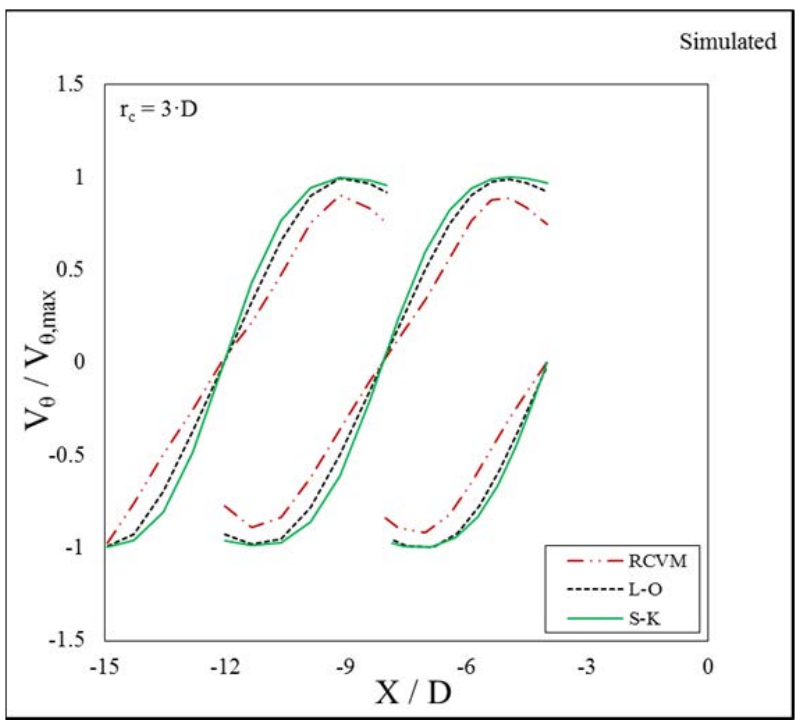

(d)

Figure 8: Comparison of vortex tangential velocity profiles defined by Eq. (3) for (a) $r_{c}=2 \cdot D$ and (b) $r_{c}=3 \cdot D$ with extracted profiles from simulations of $(c) r_{c}=2 \cdot D$ and (d) $r_{c}=3 \cdot D$.

Figures (8c) and (8d) along with Table 3 show that the $\mathrm{V}_{\theta, \max }$ for the RCVM profile is substantially altered by numerical diffusion while the L-O and S-K profiles exhibit minimal change. This is because the sharp discontinuity in the RCVM profile near $r=r_{c}$ cannot be 
accurately approximated without excessive grid refinement. The smooth and continuous L-O and S-K profiles are transported with excellent accuracy for $r_{c} \geq 3 \cdot D$ while the RCVM profile requires $r_{c} \geq 5 \cdot D$ to be transported with similar accuracy. The authors acknowledge that $\alpha$ also influences the accuracy of vortex transport; increasing or decreasing $\alpha$ sharpens or flattens the vortex profile respectively, respectively decreasing and increasing the vortex transport accuracy. However, the validation is performed with fixed $V_{\theta, \max }=1.0$, hence $\alpha=r_{c}{ }^{-1}$ making vortex transport accuracy in the present study a function of vortex size alone.

\subsection{SDOF Response Model}

The SDOF response model used in the present study is based on a simple spring-massdamper system. Eq. (7) is the system's equation of motion governing the system response $\mathrm{x}(\mathrm{t})$ to forcing $\mathrm{F}(\mathrm{t})$; significant system parameters are the mass $(\mathrm{M})$, stiffness $(\mathrm{K})$, and damping coefficient (C). The present study is concerned with studying the general dynamic response to applied forcing rather than the response of a particular system, hence it is convenient to redefine Eq. (7) as Eq. (8) by introducing definitions of the system's fundamental angular frequency “ $\omega_{\mathrm{n}}$ $=(\mathrm{K} / \mathrm{M})^{1 / 2}$ " and damping ratio " $\zeta=\mathrm{C} \cdot\left(2 \cdot \mathrm{M} \cdot \omega_{\mathrm{n}}\right)^{-1}$ ". Eq. (8) is incorporated into a computer model, and the system's response is resolved via $4^{\text {th }}$ order Runge Kutta method at each time step.

$$
\begin{array}{r}
\sum \mathrm{F}_{\mathrm{x}} \rightarrow \mathrm{M} \ddot{\mathrm{x}}+\mathrm{C} \dot{\mathrm{x}}+\mathrm{Kx}=\mathrm{F}(\mathrm{t}) \\
\ddot{\mathrm{x}}+2 \zeta \omega_{\mathrm{n}} \cdot \dot{\mathrm{x}}+\omega_{\mathrm{n}}^{2} \cdot \mathrm{x}=\mathrm{F}(\mathrm{t})
\end{array}
$$

The fundamental frequency of the response model is varied by changing its mass for a fixed stiffness value. Light damping $(\zeta=5 \%)$ is used in Section 4, when analyzing response to forcing from computer simulations, to avoid resonance when $\omega_{\mathrm{n}}$ is the same as the vortex shedding frequency. No damping $(\zeta=0)$ is used in Section 5 when analyzing response to the 
mean cross-stream force coefficient in accordance with common convention (see structural dynamics texts such as Paz \& Leigh (2004) and Chopra (2005)).

\section{Approach}

Section 4 applies cross stream force coefficient $(\mathrm{Cl})$ time histories from computersimulated vortex loading of a circular cylinder as forcing to the SDOF response model to define $\mathrm{T}_{\mathrm{v}}$. A typical $\mathrm{Cl}$ time history from computer simulation is illustrated in Figure 9a; it is decomposed in Figure $\mathbf{9 b}$ to illustrate its mean and harmonic components. The mean component is produced by surface shear and pressure resulting from the vortex's tangential wind field, and the harmonic component is produced by vortex shedding from the cylinder. Vortex shedding does not occur in tornados due to the gusty and varying wind field (Giosan \& Eng, 2013). Therefore, the present study defines the vortex forcing profile as the mean component of $\mathrm{Cl}$.

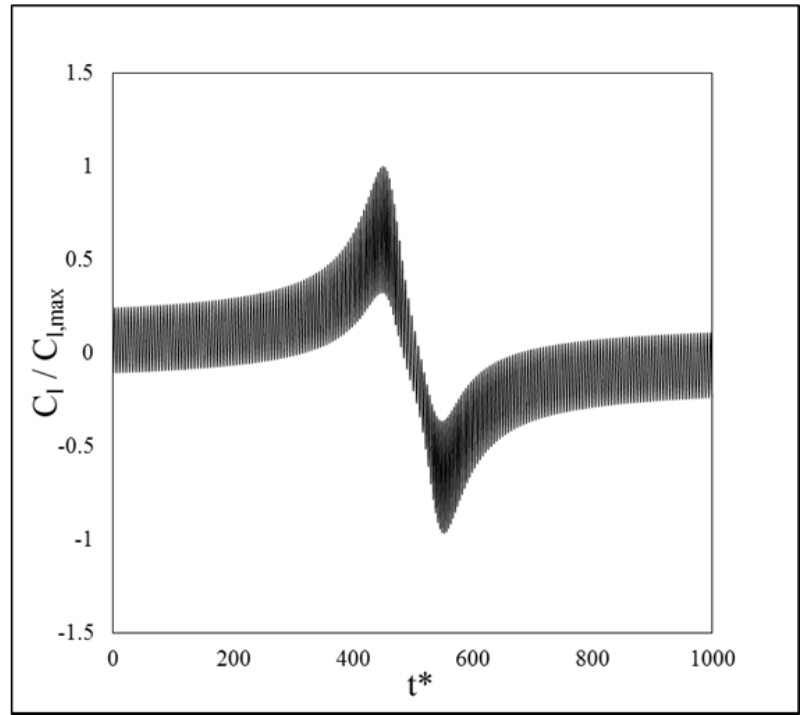

(a)

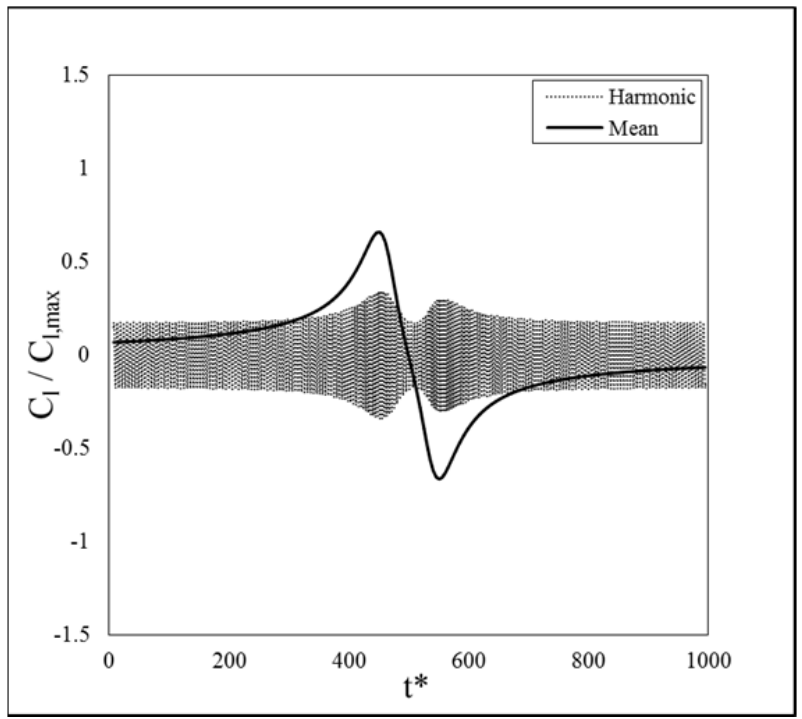

(b)

Figure 9: Time histories of the (a) lift force coefficient and (b) decomposed lift force coefficient from computer-simulated loading of a circular cylinder by a L-O vortex. 
$\mathrm{T}_{\mathrm{v}}$ is the load application period of the mean component of $\mathrm{Cl}$, and DLF analysis is used to identify $\mathrm{T}_{\mathrm{v}}$. However, the $\mathrm{Cl}$ time histories from computer simulations also contain the harmonic loading component. It is therefore necessary to identify the vortex shedding frequency ( $\left.\mathrm{f}_{\mathrm{Cl}}\right)$ so that the vortex loading frequency $\left(\mathrm{f}_{\mathrm{v}}=\mathrm{T}_{\mathrm{v}}^{-1}\right)$ can be distinguished in the DLF analysis. Therefore, DLF analysis is performed using $\mathrm{Cl}$ from a free stream simulation as forcing and $\mathrm{f}_{\mathrm{Cl}}$ is identified. Subsequent analysis is performed using $\mathrm{Cl}$ from vortex loading of the cylinder; $\mathrm{fv}$ consistently emerges as a distinct lower-frequency peak $\left(f_{\mathrm{v}}<\mathrm{f}_{\mathrm{Cl}}\right)$. DLF analysis is used to define $\mathrm{T}_{\mathrm{v}}$ as a function of the vortex's ( $\mathrm{r}_{\mathrm{c}}$ and $\mathrm{U}_{\infty}$ ) and profile (RCVM, L-O, and S-K).

Section 5 utilizes the definition of $\mathrm{T}_{\mathrm{v}}$ developed in Section 4 along with mean $\mathrm{Cl}$ time histories produced by each of the three vortex profiles to define the DLF curve for forcing produced by each profile. Definition of the DLF curves necessitates applying only the mean component of the lift force coefficient as forcing to the response model. The $\mathrm{Cl}$ time history shown in Figure 9a is for a large vortex $\left(\mathrm{r}_{\mathrm{c}}=50 \cdot \mathrm{D}\right)$, and $\mathrm{Cl}$ mean can be computed with reasonable accuracy by taking the average of envelopes bounding $\mathrm{Cl}$. However, this procedure is not applicable for loading by smaller vortices, hence an alternative approach is taken to define the mean component of $\mathrm{Cl}$. Following the example set by previous studies, empirical equations are used to define the mean $\mathrm{Cl}$ time history. Free stream simulations are utilized to define the mean and harmonic forces acting on the cylinder as function of the resultant velocity $\left(V_{R}\right)$ of the stream over the cylinder. The empirical equations are used, along with Eqs. (4a-6b) that compute the time history of $\mathrm{V}_{\mathrm{R}}$, to define the time history of $\mathrm{Cl}$ mean. After validation, the empirical equation-defined force coefficient time histories are used as forcing to define the DLF curve for each of the three profiles. 
Finally, Section 6 combines the definition of $T_{v}$ developed in Section 4, the DLF curves for the three considered vortex profiles developed in Section $\mathbf{5}$, and the documented parameter ranges of real-world tornados to assess the possible dynamic amplification of structure response to tornadic wind loads. Documented tornado parameters are summarized, and the definition of $\mathrm{T}_{\mathrm{v}}$ is used to develop the possible range of tornado load application periods. The DLF curves defined for the three vortex profiles are then used define the maximum dynamic response amplification of a structure having specified $T_{n}$. Documented $T_{n}$ values for real-world structures are surveyed and categorized so that the types of structures that may exhibit dynamic response amplification may be identified.

\section{Definition of the Vortex Load Application Period " $T_{v}$ "}

\subsection{Definition of $f_{C l}$ and $f_{v}$ by DLF Analysis}

Free stream flow over the cylinder $(\mathrm{Re}=150)$ is simulated, producing the $\mathrm{Cl}$ time history shown in Figure 10a. The lift force coefficient time history is now applied as forcing to the SDOF response model, and the resulting DLF curve is shown in Figure 10b. The DLF cuve exhibits a peak value of 9.85 approximately at the vortex shedding frequency where $f_{n} \approx f_{C l}$. The peak DLF value is very close to the theoretical maximum value DLF $=(2 \cdot \zeta)^{-1}=10.0$ for a system damped at $\zeta=5 \%$. The theoretical maximum DLF value is not attained in the present plot because the fundamental structure frequency $f_{n}=f_{C l}$ is not considered. 


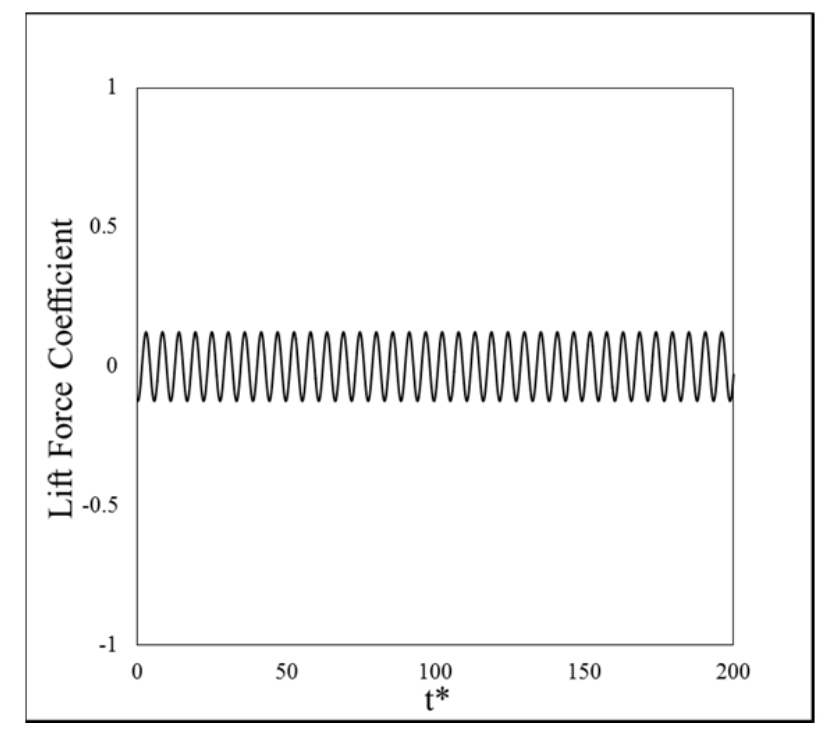

(a)

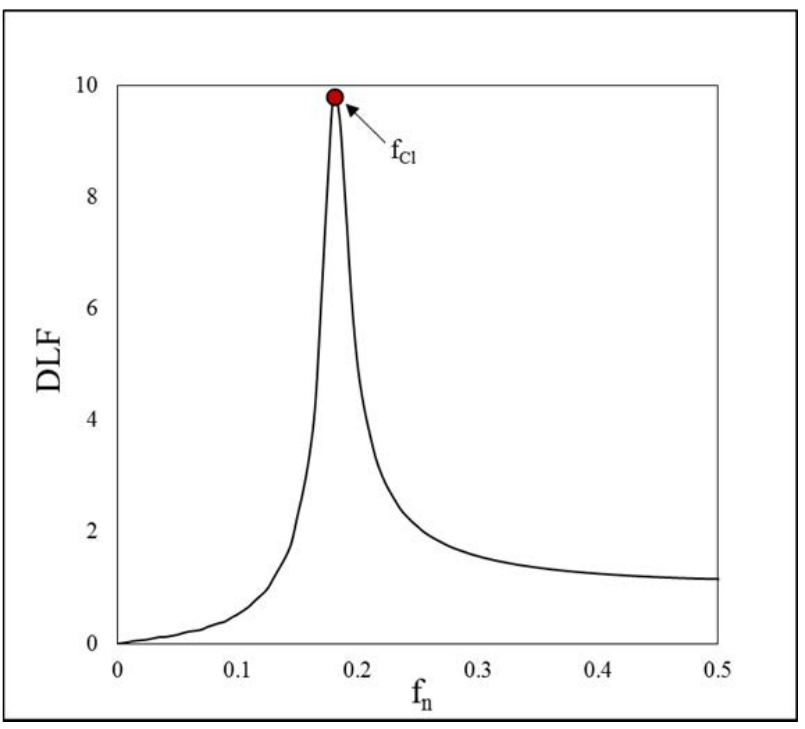

(b)

Figure 10: Free stream lift force coefficient (a) time history and (b) DLF curve.

Vortex impact with the cylinder is now simulated, and the resulting lift force coefficient time history (Figure 11a) is applied as forcing to the SDOF response model. The resulting DLF curve is shown in Figure 11b. The harmonic component of $\mathrm{Cl}$ still produces a distinct peak at $\mathrm{f}_{\mathrm{Cl}}$ (Note that the DLF amplitude at $\mathrm{f}_{\mathrm{Cl}}$ is reduced in Figure $11 \boldsymbol{b}$ because the vortex loading has greater maximum amplitude $\mathrm{F}_{\mathrm{o}}$ than $\mathrm{Cl}$ from the free stream simulation); however, there is an additional, lower-frequency peak which is labeled $f_{v}$. The vortex loading frequency $f_{v}$ is now defined as the fundamental structure frequency that exhibits the greatest dynamic response amplification to the mean component of $\mathrm{Cl}$. The subsequent subsections use the L-O vortex profile and define $T_{v}=f_{v}^{-1}$ as function of the vortex's critical radius $r_{c}$ and translational velocity $\mathrm{U}_{\infty}$. Finally, cylinder loading by RCVM and S-K vortices is simulated to establish the influence of the vortex's tangential velocity profile on $\mathrm{T}_{\mathrm{v}}$. 


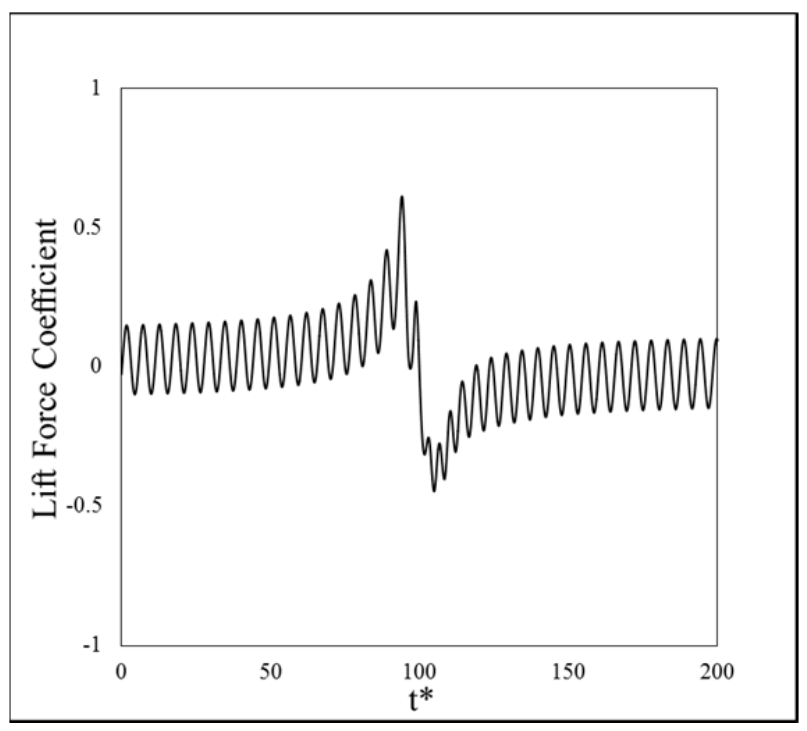

(a)

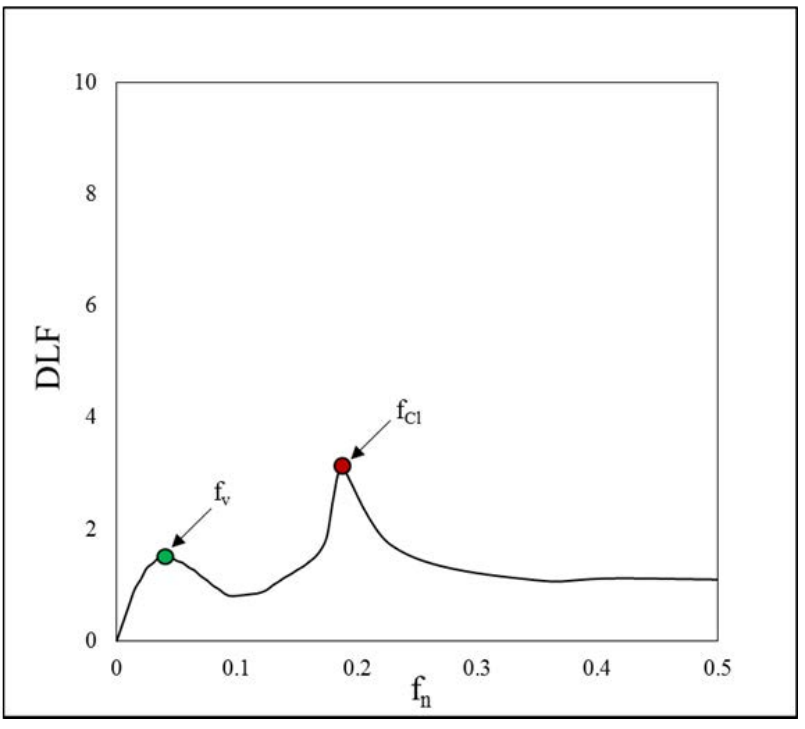

(b)

Figure 11: Vortex loading lift force coefficient (a) time history and (b) DLF curve.

\subsection{Influence of Vortex Size on $T_{v}$}

Definition of $T_{v}$ begins by evaluating the influence of the vortex's size, specifically $r_{c}$, on the vortex loading period. The L-O vortex profile is used, the vortex's velocity is $\mathrm{V}_{\theta, \max }=\mathrm{U}_{\infty}=$ 1.0 , and the size of the vortex is varied from $2 \leq r_{c} / D \leq 10$. Vortex loading of the cylinder is simulated for each vortex size, and the resulting $\mathrm{Cl}$ time histories are applied as forcing to the SDOF response model. Figure 12a illustrates the resulting DLF curves, and Figure $\mathbf{1 2} \boldsymbol{b}$ is a zoomed view of the $f_{v}$ peaks. 


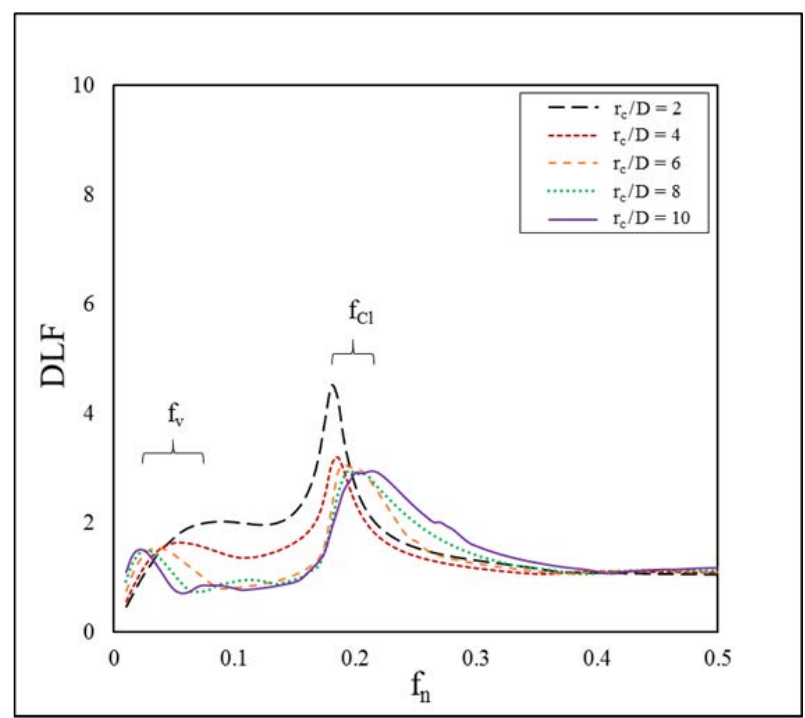

(a)

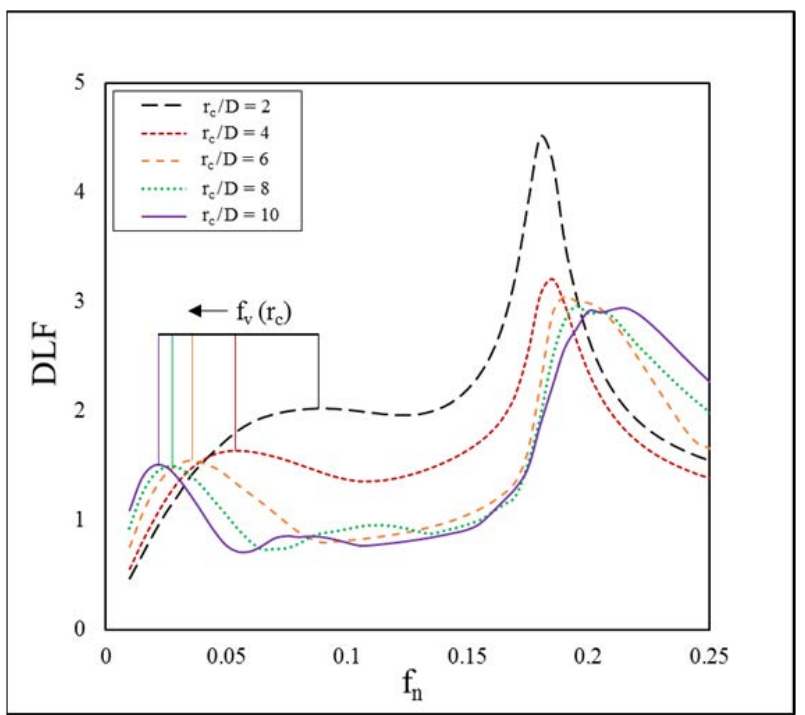

(b)

Figure 12: (a) Lift force coefficient DLF curves and (b) zoomed view of $f_{v}$ illustrating the progressive decrease in $f_{v}$ with increasing $r_{c}$.

Two general observations are made from the DLF curves in Figures $12 \boldsymbol{a}$ and $\mathbf{1 2 b}$. First, the DLF curve peaks associated with $\mathrm{f}_{\mathrm{Cl}}$ progressively move right-ward and broaden as $\mathrm{r}_{\mathrm{c}}$ increases. This is because the larger impinging vortex progressively augments the velocity of the stream over the cylinder pre-impact, hence $\mathrm{f}_{\mathrm{Cl}}$ progressively increases. Second, $\mathrm{f}_{\mathrm{v}}$ progressively decreases with $r_{c}$ as shown in Figure $12 \boldsymbol{b}$; this implies that $T_{v}$ progressively increases with $r_{c}$. Intuitively, this is because a larger vortex interacts with the cylinder for longer time, hence the load application period is longer.

Vortex loading frequency values (marked by vertical lines in Figure 12b) are extracted and inverted to give the vortex loading period for each considered $r_{c}$. The vortex load application period $T_{v}$ is then plotted as function of $r_{c}$ as shown in Figure 13a, revealing that $T_{v}\left(r_{c}\right)$ is a linear trend. The slope of $\mathrm{T}_{\mathrm{v}}\left(\mathrm{r}_{\mathrm{c}}\right)$, is now defined as the dimensionless vortex loading period " $\mathrm{T}_{\mathrm{v}}$ "”. The dimensionless vortex loading period $\mathrm{T}_{\mathrm{v}}{ }^{*}$ corresponds to the dimensionless region of the vortex's tangential velocity profile that is illustrated in Figure $\mathbf{1 3 b}$ for the L-O vortex. It is postulated that 
$T_{v}$ is the time required for the portion of the vortex's tangential velocity profile defined by $T_{v}{ }_{v}^{*}$ to cross the loaded structure.

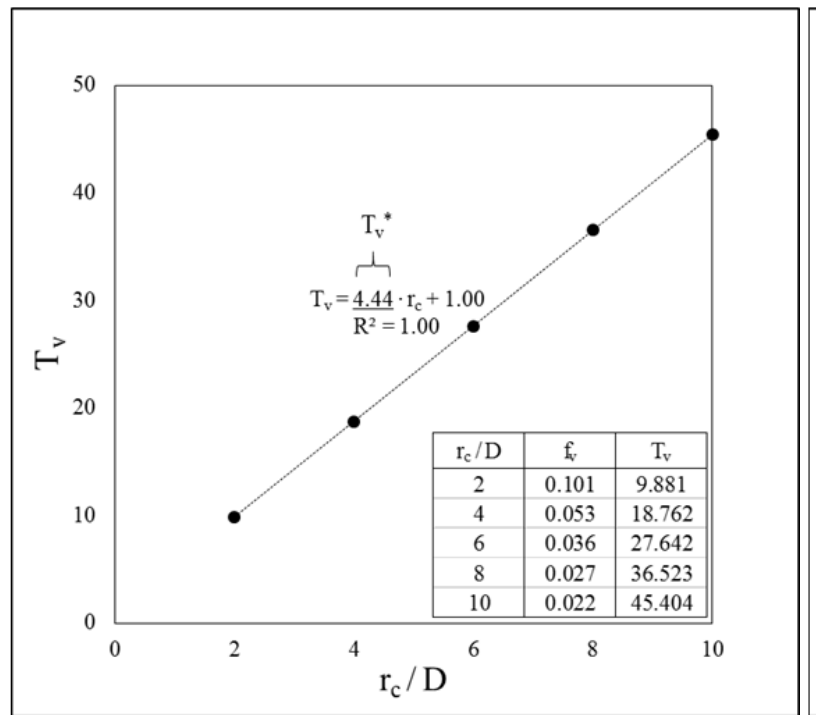

(a)

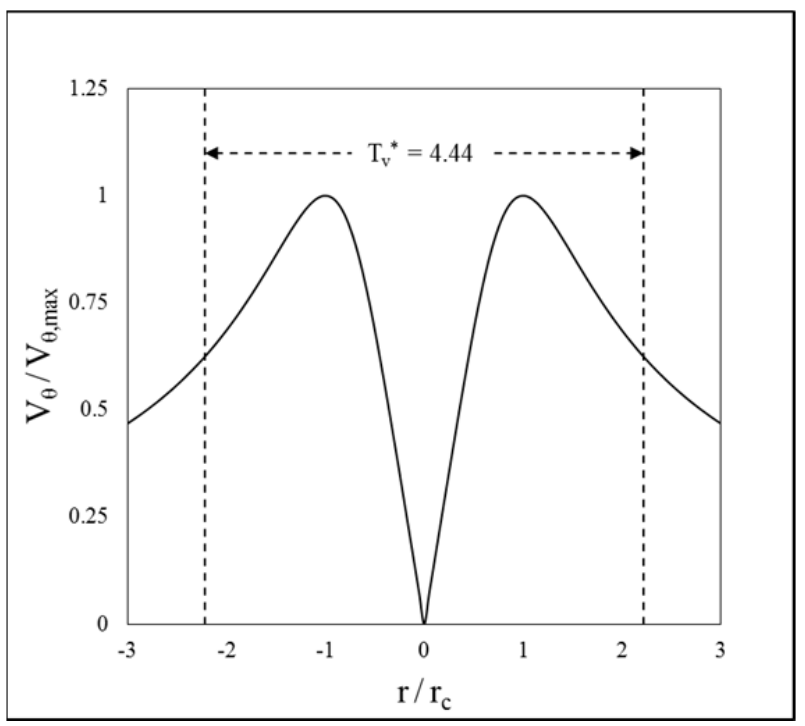

(b)

Figure 13: (a) Vortex loading period as function of vortex critical radius for $2 \leq r_{c} / D \leq 10$ and (b) dimensionless region of the L-O vortex's tangential velocity profile corresponding to $T_{v}$.

\subsection{Influence of Vortex Translational Velocity on $T_{v}$}

DLF analysis is now used to evaluate the influence of the impinging vortex's translational velocity on $\mathrm{T}_{\mathrm{v}}$. The L-O vortex profile is used, the vortex's tangential velocity is $\mathrm{V}_{\theta, \max }=1.0$, the vortex's translational velocity is varied from $1.0 \leq \mathrm{U}_{\infty} \leq 2.0$, and the size of the vortex is varied from $2 \leq r_{c} / D \leq 10$. The vortex load application period $T_{v}$ decreases when $r_{c}$ decreases or $U_{\infty}$ increases, hence $f_{v}$ approaches $f_{C l}$ and there is no distinct peak in the DLF curve for some combinations of $r_{c}$ and $U_{\infty}$. The resulting $T_{v}$ values for each $U_{\infty}$ are summarized and curve fit in Figure 14a. 


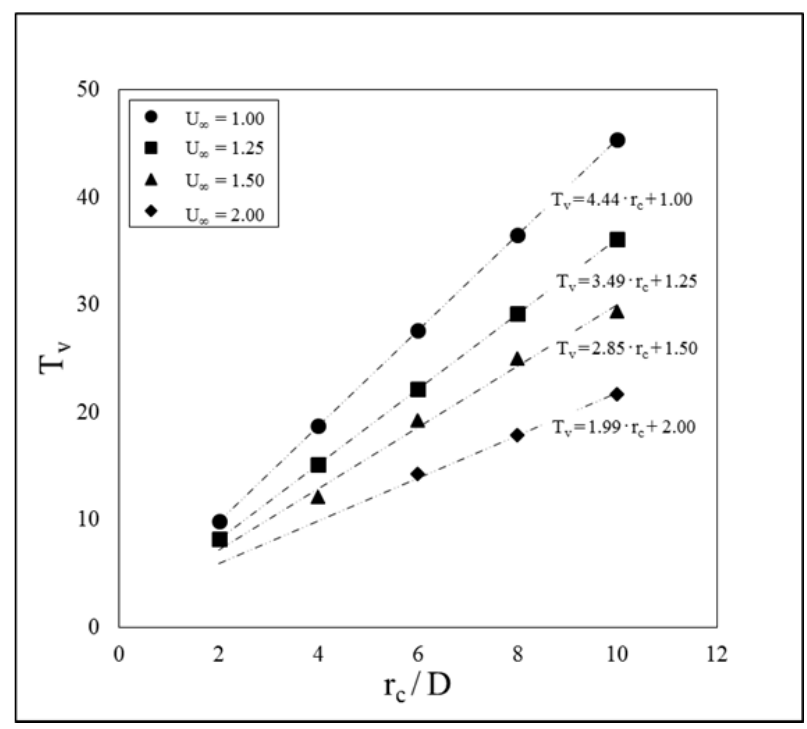

(a)

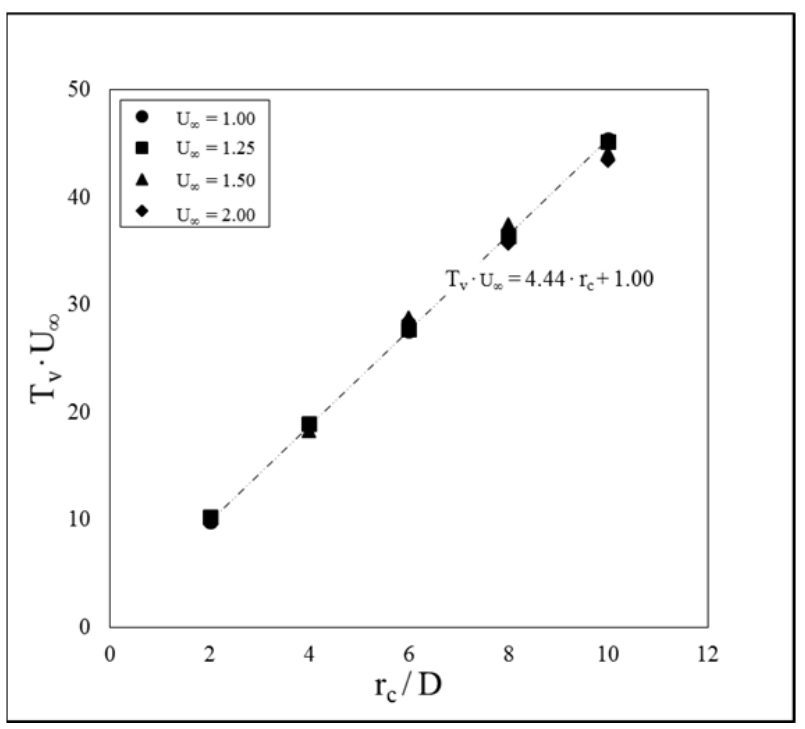

(b)

Figure 14: (a) Vortex loading period as function of vortex translational velocity and (b) collapse of vortex loading period curves using the definition of Eq. (9).

The trend $\mathrm{T}_{\mathrm{v}}\left(\mathrm{r}_{\mathrm{c}}\right)$ remains linear for all $\mathrm{U}_{\infty}$ values, and, as one would expect, increasing the vortex's translational velocity decreases the associated value of $\mathrm{T}_{\mathrm{v}}$. The postulation raised in the previous subsection, specifically that $T_{\mathrm{v}}$ is the time required for the portion of the dimensionless vortex profile defined by $\mathrm{T}_{\mathrm{v}}{ }^{*}$ to cross the loaded structure is defined by Eq. (9).

$$
\mathrm{T}_{\mathrm{v}}=\mathrm{T}_{\mathrm{v}}^{*} \cdot \mathrm{r}_{\mathrm{c}} \cdot \mathrm{U}_{\infty}^{-1}
$$

The data plotted in Figure 14a are now re-plotted in Figure $\mathbf{1 4 b}$ using the definition of $\mathrm{T}_{\mathrm{v}}$ defined by Eq. (9). The $\mathrm{T}_{\mathrm{v}}\left(\mathrm{r}_{\mathrm{c}}\right)$ curves compress to the trend line previously defined in Figure 13a (Defined using $\mathrm{U}_{\infty}=1$ ). This confirms the postulation that $\mathrm{T}_{\mathrm{v}}$ is the time required for the dimensionless region of the vortex profile defined by $\mathrm{T}_{\mathrm{v}}{ }^{*}$ to cross the loaded structure. Eq. (9) establishes the generalized relationship between $T_{v}$ and the two vortex parameters $r_{c}$ and $U_{\infty}$. Now the influence of the impinging vortex's profile on the dimensionless vortex period $\mathrm{T}_{\mathrm{v}}{ }^{*}$ is all that need be established to define $\mathrm{T}_{\mathrm{v}}$.

\subsection{Influence of Vortex Profile on $T_{v}$}


Figure $\mathbf{5} \boldsymbol{b}$ shows that the RCVM, L-O, and S-K profiles represent the possible range of tornado-vortex tangential velocity profiles. The wind profiles, and consequently the forcing profiles that they produce, range from sharp (RCVM) to smooth (S-K). The dynamic amplification of a loaded structure's response depends upon the profile of the applied forcing, and it is postulated that $T_{v}$, for given $r_{c}$ and $U_{\infty}$, depends upon the vortex profile as well. The methodology developed in Sections 4.2-4.3 is now utilized to define $T_{v}$ for the RCVM and S-K vortex profiles, and $\mathrm{T}_{\mathrm{v}} \cdot \mathrm{U}_{\infty}$ being summarized in Figure 15a for the three vortex profiles.

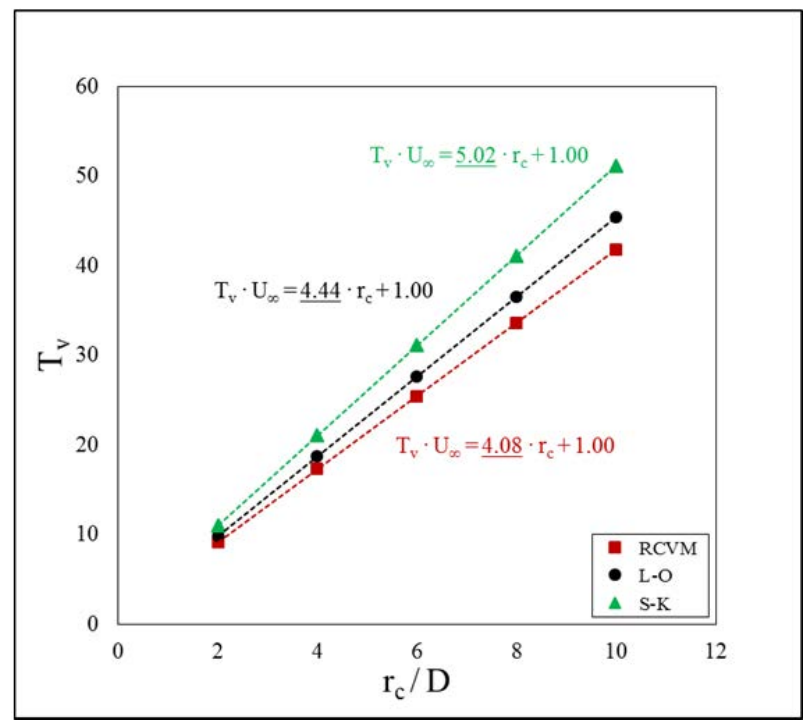

(a)

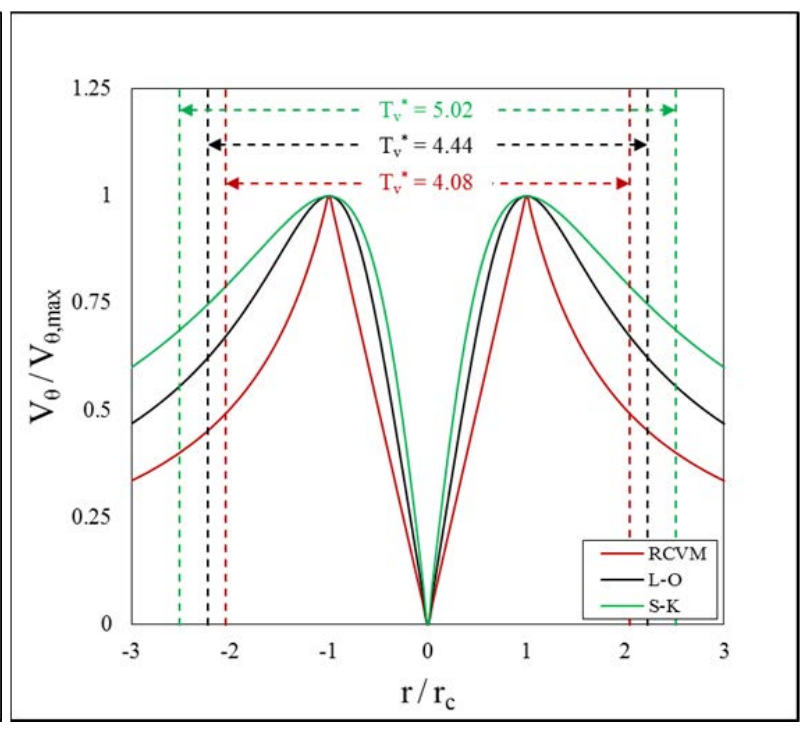

(b)

Figure 15: (a) Definition of $T_{v}\left(r_{c}\right)$ for the three vortex profiles and (b) dimensionless regions of the three vortex tangential velocity profiles corresponding to $T_{v}{ }_{v}$.

Figure 15a shows that $T_{v}\left(r_{c}\right)$ is a linear trend for all of the vortex profiles. Furthermore, $T_{v}$ lengthens when the vortex's profile flattens (S-K profile) and shortens when the vortex's profile becomes more peaked (RCVM profile). The definition of $\mathrm{T}_{\mathrm{v}}{ }^{*}$ is retained and illustrated for the three vortex profiles in Figure 15b. The influences of the vortex size, translational velocity, and velocity profile on $T_{v}$ have now been evaluated and integrated into the definition Eq. (9). Therefore, Eq. (9) can now be used to define $T_{v}$ for a vortex having known parameters and profile. 


\section{Definition of DLF Curves for Vortex Loading}

DLF curves are to be defined using the mean components of $\mathrm{Cl}$ produced by each of the three considered vortex profiles. The harmonic component of $\mathrm{Cl}$ cannot be easily removed from the $\mathrm{Cl}$ time histories from computer-simulated vortex loading of the cylinder. Therefore, the two subsequent subsections respectively develop and validate empirical force coefficient equations to define the mean $\mathrm{Cl}$ time history. The equation-defined forcing is then applied to the SDOF response model and DLF curves for each vortex profile are defined.

\subsection{Definition of Empirical Force Coefficient Equations}

Figure 16a illustrates a cylinder immersed in a free stream and the forces acting on it. The mean force component $\left(\mathrm{C}_{\mathrm{M}}\right)$ acts in the direction of the stream, and the harmonic component $\left(\mathrm{C}_{\mathrm{H}}\right)$ acts normal to the stream direction. Typical notation is to assign the $\mathrm{x}$-axis along the free stream direction and to define the $\mathrm{x}$-direction force as drag $\mathrm{Cd}=\mathrm{C}_{\mathrm{M}}$. The $\mathrm{y}$-axis is then assigned normal to the free stream direction, and the y-direction force is defined as lift $\mathrm{Cl}=\mathrm{C}_{\mathrm{H}}$.

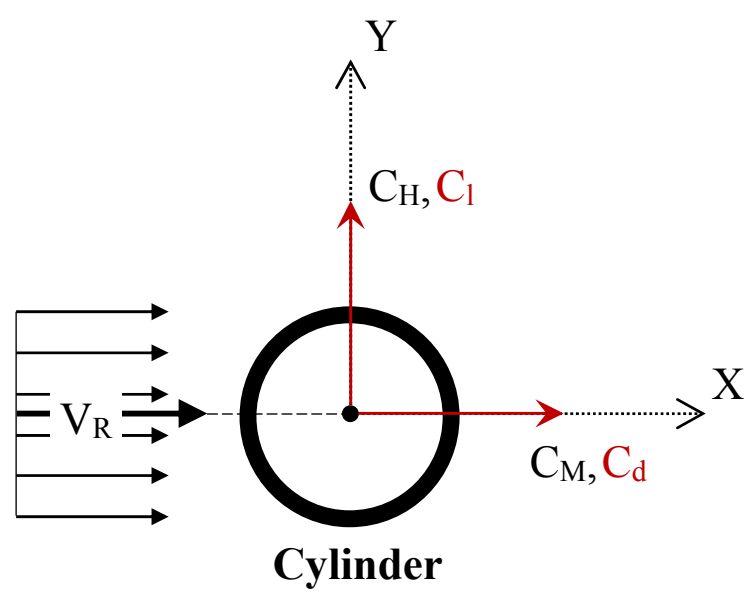

(a)

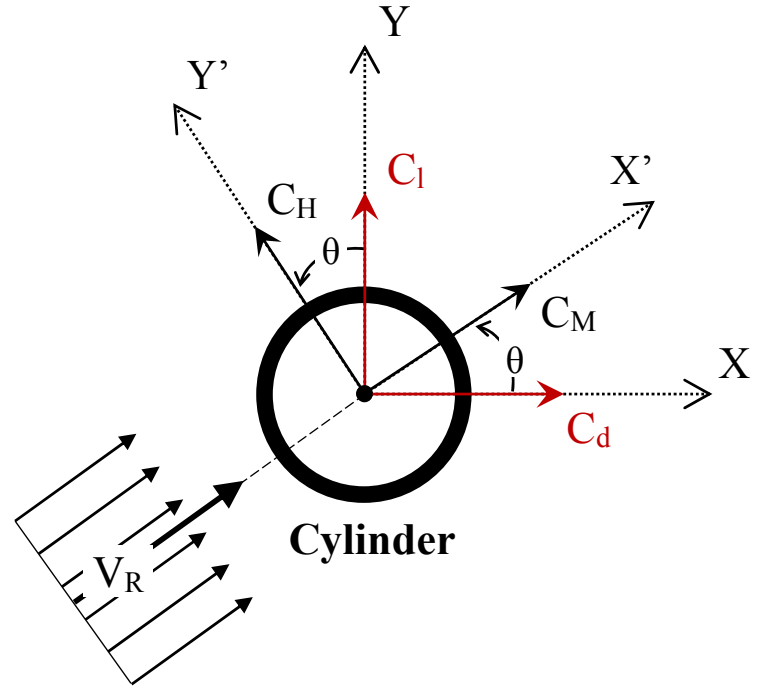

(b)

Figure 16: Schematic of forces on a cylinder due to (a) a free stream and (b) a stream incident from any direction. 
When a vortex is added to the free stream, the direction and magnitude of the resultant velocity " $V_{R}$ " changes as the vortex moves relative to the cylinder. Consequently, the directions in which $C_{M}$ and $C_{H}$ act are shifted by " $\theta$ " (See Figure 16b), which is the direction of the resultant velocity on the cylinder surface defined in Eq. (10), and "V" and "U" are the vertical and horizontal components of " $\mathrm{V}_{\mathrm{R}}$ " respectively. The resulting drag and lift force coefficients are resolved in Eqs. (10-12).

$$
\begin{gathered}
\theta=\tan ^{-1}(\mathrm{~V} / \mathrm{U}) \\
\mathrm{Cd}=\mathrm{C}_{\mathrm{M}} \cdot \cos (\theta)-\mathrm{C}_{\mathrm{H}} \cdot \sin (\theta) \\
\mathrm{Cl}=\mathrm{C}_{\mathrm{M}} \cdot \sin (\theta)+\mathrm{C}_{\mathrm{H}} \cdot \cos (\theta)
\end{gathered}
$$

It is assumed that the impinging vortex is much larger than the cylinder, hence, the same $V_{R}$ is incident across the cylinder's surface. Furthermore, $V_{R}$ is approximately the resultant velocity that would be present at the location of the cylinder center if the cylinder were not present. The fluid viscosity " $v=150$ " and cylinder diameter " $\mathrm{D}=1$ " are fixed, hence $\mathrm{C}_{\mathrm{M}}$ and $\mathrm{C}_{\mathrm{H}}$ are only functions of $V_{R}$. Computer-simulated cylinder loading by free streams (Illustrated in Figure 16a) are used to establish empirical relationships for $C_{M}$ and $C_{H}$ with respect to $V_{R}$. Emperical force coefficients are developed for the range $V_{R}=0.67(R e=100)$ to $V_{R}=2.0(R e=$ 300 ); the upper bound is limited because the presently-used 2D computer model is only validated to $\mathrm{Re} \approx 300$. Resulting values of $\mathrm{C}_{\mathrm{M}}$ and $\mathrm{C}_{\mathrm{H}}$, computed with $\mathrm{U}_{\text {ref }}$ of 2.0 , are summarized and curve fit in Figure 17, yielding Eqs. (13-14) which define $C_{M}$ and $C_{H}$ with respect to $V_{R}$. It should be noted that $C_{M}$ and $C_{H}$ are actually functions of Re. However, $V_{R}$ is used as the dependent variable because similar curve fits of $\mathrm{C}_{\mathrm{M}}$ and $\mathrm{C}_{\mathrm{H}}$ as functions of Re require the use of 5+ significant digits. Therefore, $V_{R}$ is used here to make Eqs. (13) and (14) less cumbersome. 


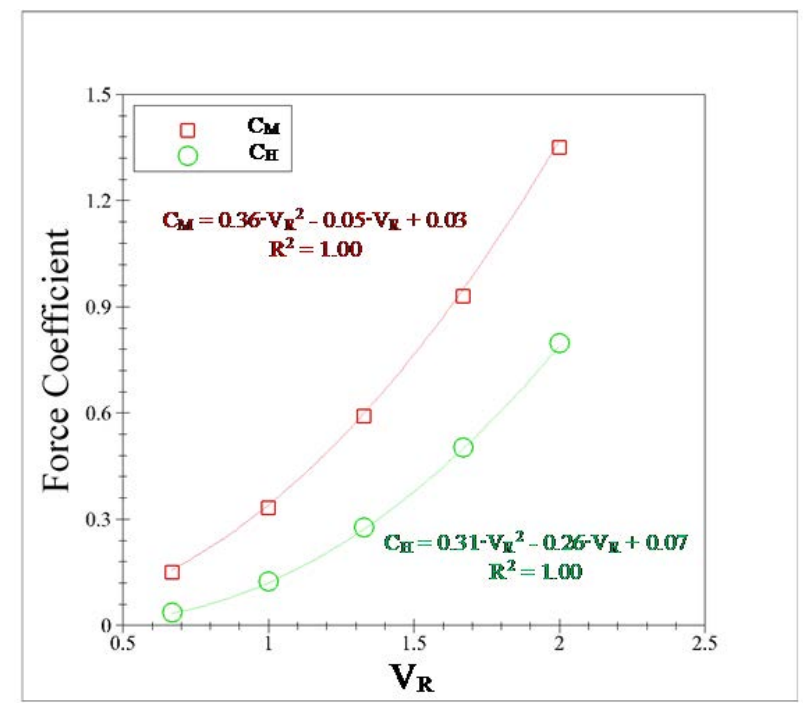

Figure 17: Mean force coefficient $C_{M}$ and harmonic force coefficient amplitude $C_{H}$ as function of resultant velocity of the incident stream.

$$
\begin{aligned}
& C_{M}=0.36 \cdot V_{R}^{2}-0.05 \cdot V_{R}+0.03 \\
& C_{H}=0.31 \cdot V_{R}^{2}-0.26 \cdot V_{R}+0.07
\end{aligned}
$$

\subsection{Assessment of Empirical Equations (10-14)}

The fundamental assumption for using Eqs. (10-14) to define the cylinder loading by the vortex is that the impinging vortex is much larger than the cylinder so that the cylinder surface is exposed to $V_{R}$ that would be at the location of the cylinder center. The capability of Eqs. (10-14) to replicate forcing produced computer-simulated vortex impact with the cylinder is first assessed by simulating impact of a large vortex having $r_{c}=50 \cdot D$ with the cylinder. The maximum velocity within the domain is the sum of the maximum vortex tangential velocity and the vortex translational velocity $\mathrm{V}_{\theta, \max }+\mathrm{U}_{\infty}=2.0$. Two vortex velocity ratios (the ratio of the maximum vortex tangential velocity to the vortex translational velocity), specifically $\mathrm{V}_{\theta, \max } / \mathrm{U}_{\infty}=$ 1.0 and $\mathrm{V}_{\theta, \max } / \mathrm{U}_{\infty}=4.3$, are used to assess the accuracy with which Eqs. (10-14) replicated force coefficient time histories from CFD simulations. Figures $\mathbf{1 8 a}$ and $\mathbf{1 8 b}$ show comparison of force coefficient time histories from the computer simulations with time histories defined by Eqs. (10- 
14) for the respective vortex velocity ratios. In both cases, the force coefficient time histories produced by CFD simulation are replicated with exceptional accuracy by Eqs. (10-14).

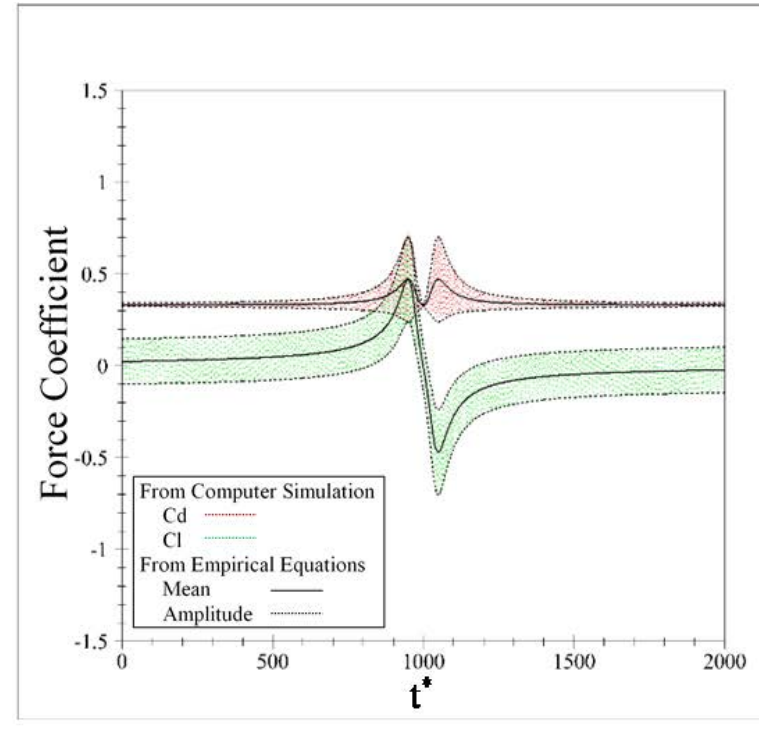

(a)

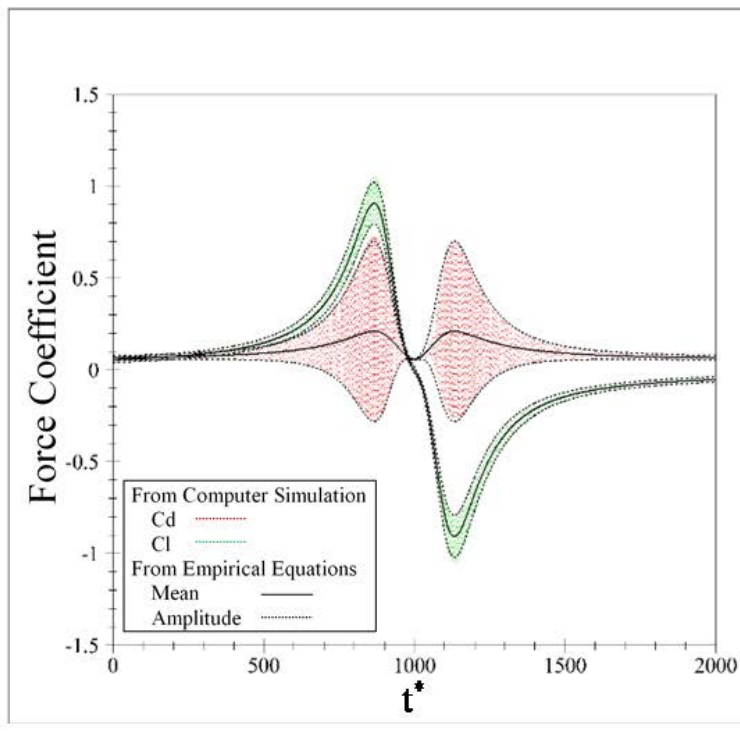

(b)

Figure 18: Comparison of force coefficient time histories from computer simulation and defined by the emperical equations Eqs. (10-14): (a) $\mathrm{V}_{\theta, \max } / \mathrm{U}_{\infty}=1.0$ and (b) $\mathrm{V}_{\theta, \max } / \mathrm{U}_{\infty}=4.3$.

The assumption that the cylinder surface is exposed to $V_{R}$ becomes increasingly erroneous as the size of the impinging vortex decreases. Therefore, the second stage in evaluating the applicability of Eqs. (10-14) is to compare dynamic loading produced by their defined forcing with dynamic loading produced by forcing from computer-simulated vortex impact. The study performed in Sections $4.2-4.3$ is repeated using mean lift force coefficient time histories defined by Eqs. (10-14) as the applied forcing. The considered vortex size range is $2 \leq r_{c} / D \leq 10$, the vortices' velocity is fixed at $V_{\theta, \max }=U_{\infty}=1.0$, and all three vortex profiles are used in the the validation study.

Mean $\mathrm{Cl}$ time histories defined by Eqs. (10-14) for the three vortex profiles are illustrated in Figures 19.1a-19.1c. DLF analysis is performed applying each of the three $\mathrm{Cl}$ time histories as forcing; summary and comparison of the resulting $\mathrm{T}_{\mathrm{v}}\left(\mathrm{r}_{\mathrm{c}}\right)$ with the definition given by Eq. (9) is shown in Figures 19.2a - 19.2c. Mean $\mathrm{Cl}$ time histories defined by Eqs. (10-14) consistently 
produce maximum dynamic response amplification for the same $\mathrm{T}_{\mathrm{n}}$ as does $\mathrm{Cl}$ mean from computer simulation. This confirms that the equation-defined $\mathrm{Cl}$ mean produces the same dynamic response as $\mathrm{Cl}$ mean from computer simulation, hence equation-defined forcing may now be used to define the DLF curves.

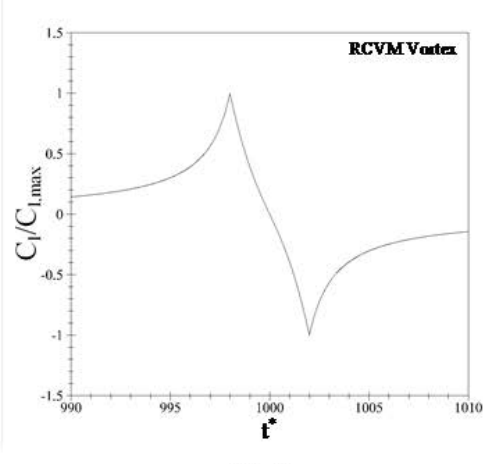

(1a)

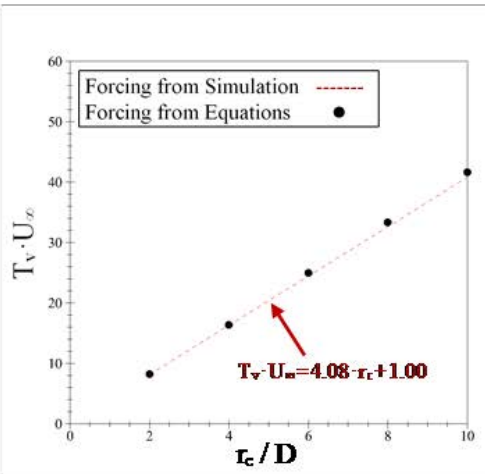

(2a)

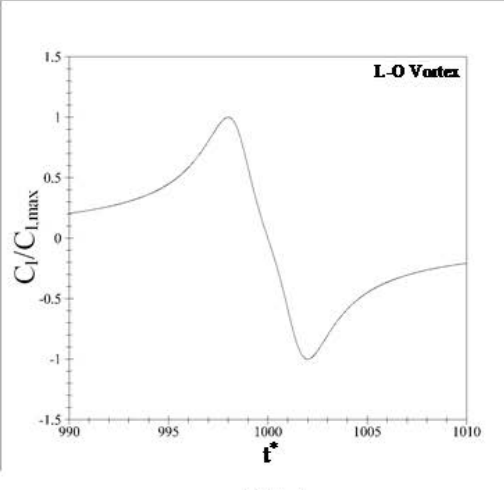

(1b)

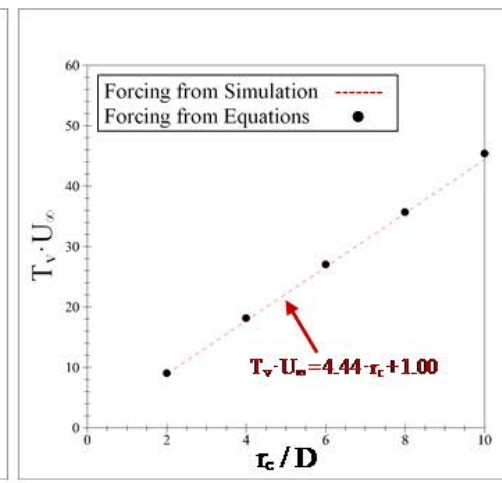

(2b)

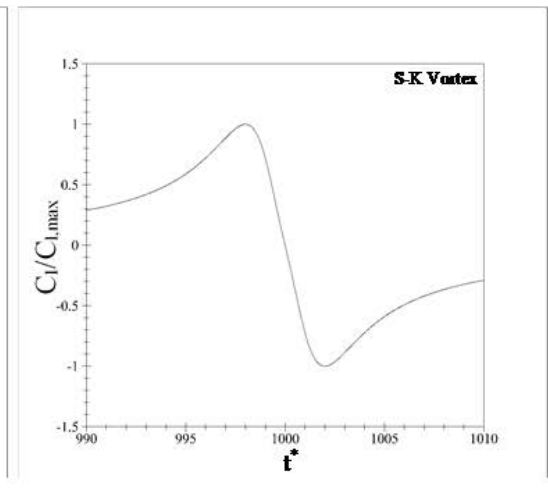

(1c)

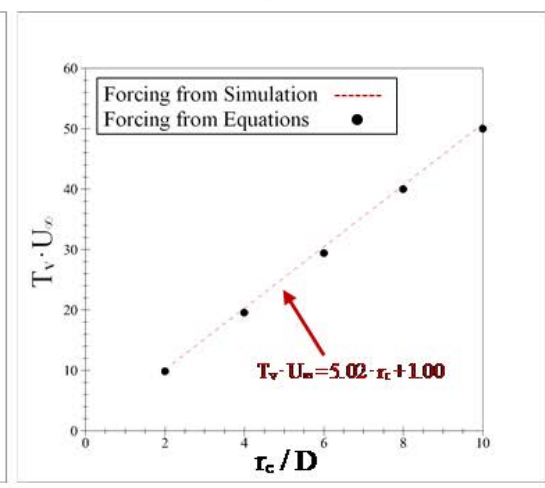

(2c)

Figure 19: (1) Mean lift force coefficient time histories for (a-c) RCVM, L-O, and S-K vortices and (2) comparison of $T_{v}$ from DLF of equation-defined forcing (black dots) with Eq. (9) (dashed line).

\subsection{Definition of Vortex Loading DLF Curves}

Mean $\mathrm{Cl}$ time histories defined by Eqs. (10-14) for each of the three vortex profiles are now applied as forcing to the SDOF response model. The fundamental frequency $T_{n}$ of the SDOF structure is incremented through a specified range, and the maximum DLF value is extracted for each $T_{n}$. These maximum values are compiled allowing the trend $\operatorname{DLF}\left(T_{v} / T_{n}\right)$, which is referred to as the DLF curve, to be plotted for each profile. Figures 20a-20c 
summarize the DLF curves for the mean $\mathrm{Cl}$ produced by the RCVM, L-O, and S-K vortex profiles respectively. The subplots in the upper-right corner of each plot indicate $T_{v}$, which is the portion of the mean $\mathrm{Cl}$ time history that produces the dynamically-amplified structure response.

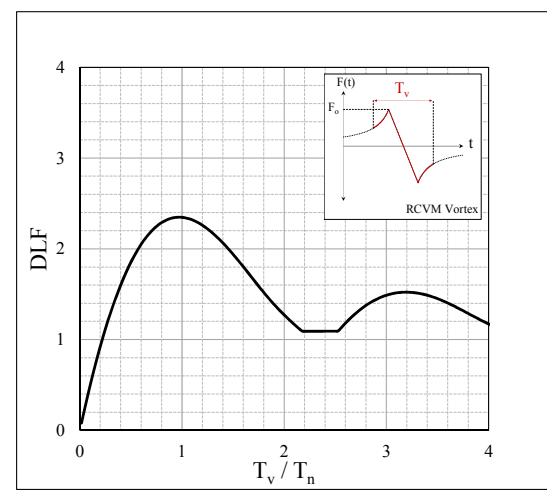

(a)

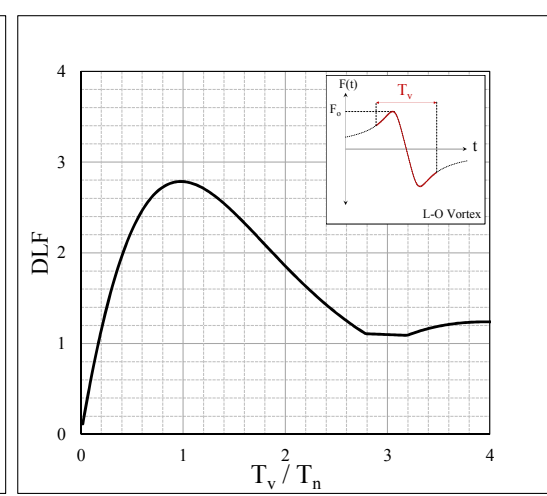

(b)

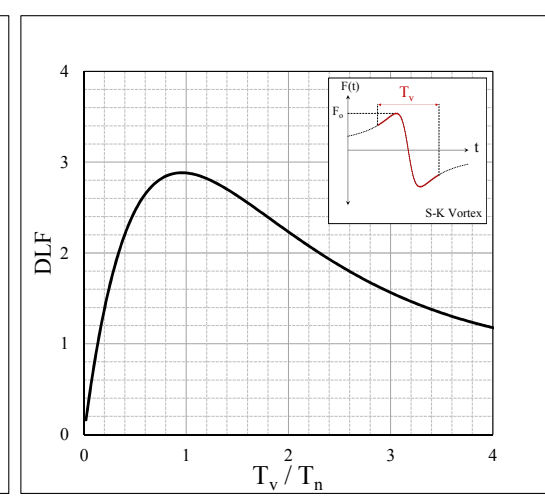

(c)

Figure 20: DLF curves for vortex loading by vortices having (a) RCVM, (b) L-O, and (c) S-K tangential velocity profiles.

The vortex loading DLF curves change in two primary ways as the vortex profile transitions from sharp (RCVM) to smooth (S-K). First, the maximum value of the DLF curve progressively increases: 2.35 (RCVM) $\rightarrow 2.78$ (L-O) $\rightarrow 2.88$ (S-K) as the vortex's profile flattens. Additionally, the pronounced, secondary peaks in the DLF curve (Figure 20a) flatten (Figure 20b) and disappear (Figure 20c) as the vortex profile flattens (RCVM to S-K profile). Both of these trends are observed when DLF curves for the sharp triangle wave and the smooth sine wave (Figures $2 \boldsymbol{a}$ and $2 \boldsymbol{b}$ ) are compared, thereby providing qualitative validation of the methodology used to define the vortex loading DLF curves Figures 20a-20c. Now the definition of $T_{v}$ given by Eq. (9) and the vortex loading DLF curves can be used to define the dynamic amplification of a specified structure's response to loading by a specified vortex.

\section{Definition of General DLF Curve for Tornado Wind Loads}

Section 4 develops Eq. (9) to compute the vortex load application period $\mathrm{T}_{\mathrm{v}}$ based upon the vortex's size $r_{\mathfrak{c}}$, translational velocity $\mathrm{U}_{\infty}$, and tangential velocity profile. Section 5 develops 
DLF curves defining the maximum dynamic response amplification for a structure having specified fundamental period $\mathrm{T}_{\mathrm{n}}$. Now Section 6 combines the findings in the previous two sections along with the documented range of tornado vortex parameters to define a generalized DLF curve for structure response to tornado wind loadings.

\subsection{Documented Tornado-Vortex Parameters and Fundamental Structure Period Ranges}

The vortex loading period defined in Eq. (9) is a function of two vortex parameters, $r_{c}$ and $\mathrm{U}_{\infty}$, and the vortex's tangential velocity profile, the influence of which is integrated through $\mathrm{T}_{\mathrm{v}}{ }^{*}$. The authors acknowledge that it is not possible to define the range of tornado vortex parameters with complete confidence because vortex parameters change continuously and are notably different between storms. Furthermore, both technological limitations and the random nature of tornado occurrence limit the documentation of tornado properties. However, the tornado-vortex parameters reported herein are compiled following extensive review of extreme tornado events, and the parameters summarized in Table 4 are believed to represent the documented severe-storm parameter range. The minimum vortex translational velocity $\mathrm{U}_{\infty}$ could be taken as zero because tornados have been observed to come to a standstill at times; however, such a case would no longer produce a transient loading event. Table 4 also includes the dimensionless vortex period $\mathrm{T}_{\mathrm{v}}{ }^{*}$ range previously reported in Figure 15a.

Table 4: Real-world tornado vortex parameters.

\begin{tabular}{|c|c|c|c|}
\hline Parameter & Units & Minimum & Maximum \\
\hline $\mathrm{r}_{\mathrm{c}}$ & $\mathrm{m}$ & 46.0 (Fujita, 1981) & 2008.0 (NOAA, 2013a) \\
\hline $\mathrm{U}_{\infty}$ & $\mathrm{m} \cdot \mathrm{s}^{-1}$ & 11.6 (NOAA, 2013b) & 32.6 (Fujita, 1973) \\
\hline $\mathrm{T}_{\mathrm{v}}{ }^{*}$ & $\sim \sim \sim$ & 4.08 & 5.02 \\
\hline
\end{tabular}

Measured fundamental periods of real-world structures, which are summarized in Table 5 , vary greatly, ranging from rigid, single-story concrete structures $\left(T_{n}=0.035 \mathrm{~s}\right)$ to very flexible structures such as the main span of the Golden Gate Bridge $\left(T_{n}=18.2 \mathrm{~s}\right)$. For future discussion, 
it is convenient to define four groups of structures based upon their fundamental periods: "G1 Wood Frame" $\left(0.15 \leq \mathrm{T}_{\mathrm{n}} \leq 0.55\right)$, "G2 - Reinforced Concrete" $\left(0.04 \leq \mathrm{T}_{\mathrm{n}} \leq 3.19\right)$, "G3 - Poles and Chimneys" $\left(0.49 \leq T_{n} \leq 3.57\right)$, and "G4 - Steel Structures" $\left(0.60 \leq T_{n} \leq 7.00\right)$.

Table 5: Fundamental periods for real-world structures.

\begin{tabular}{|c|c|c|c|}
\hline Structure & Description & $\mathrm{T}_{\mathrm{n}}(\mathrm{s})$ & Source \\
\hline \multicolumn{4}{|c|}{ Wood-Frame Structures } \\
\hline $\begin{array}{c}\text { "Typical" Single-Story Residence } \\
\ldots \\
\text { 4-Story Structure on CC Slab } \\
\ldots \\
\text { 5-Story Structure on CC Slab }\end{array}$ & $\begin{array}{l}\text { Undamaged } \\
\text { Damaged } \\
\text { Undamaged } \\
\text { Damaged } \\
\mathrm{H}=15.24 \mathrm{~m}\end{array}$ & $\begin{array}{c}0.15 \text { to } 0.20 \\
\quad<0.50 \\
0.233 \text { to } 0.250 \\
0.345 \text { to } 0.370 \\
0.40 \text { to } 0.55\end{array}$ & $\begin{array}{c}\text { Graf (2008) } \\
\ldots \\
\text { Hafeez et al. (2014) } \\
\ldots \\
\text { Thompson (2015) }\end{array}$ \\
\hline \multicolumn{4}{|c|}{ Civil Structures \& Skyscrapers } \\
\hline $\begin{array}{c}\text { Shear Wall Structures } \\
\text {... } \\
\text { Buildings with Load Bearing Walls \& } \\
\text { Moment-Resisting Frames } \\
\text { Nuclear Reactor Housing } \\
13 \text { Buildings with Load Bearing Walls } \\
\text { Morrow Point Dam } \\
37 \text { Moment-Resisting Frame Structures } \\
\text { PineFlat Dam } \\
\text { 21 Buildings in LA, CA } \\
53 \text { Moment-Resisting Frame Structures } \\
\text { Medical Center, Richmond CA } \\
\text { National Health/Welfare Building } \\
\text { Alcoa Building } \\
\text { Transamerica Building } \\
\text { Golden Gate Bridge Main Span } \\
601 \text { Lexington Ave. (Citigroup Cent.) } \\
\text { Burj Khalifa } \\
\end{array}$ & $\begin{array}{c}\text { RC, }(12 \times 8 \times 5.6 \mathrm{~m}) \\
\text { RC, }(27 \times 24 \times 42 \mathrm{~m}) \\
\text { RC, }(71 \times 10.98 \times 8.45 \mathrm{~m}) \\
\text { RC, }(51.64 \times 17 \times 77.1 \mathrm{~m}) \\
\text { RC, Dome-Roofed } \\
\text { RC, H }=15 \mathrm{~m} \\
\text { RC, H=139 m } \\
\text { RC, } 9<\mathrm{H}<91 \mathrm{~m} \\
\text { RC, } \mathrm{H}=122 \mathrm{~m} \\
\text { RC \& Steel, } 20<\mathrm{H}<100 \mathrm{~m} \\
\text { Steel, } 12.5<\mathrm{H}<257 \mathrm{~m} \\
\text { Steel, H } \approx 10 \mathrm{~m} \\
\text { RC \& Steel, }(43 \times 27 \times 72 \mathrm{~m}) \\
\text { Steel, H }=120 \mathrm{~m} \\
\text { Steel, H=260 m } \\
\mathrm{L}=1280 \mathrm{~m} \\
\text { RC \& Steel, H=279 m } \\
\mathrm{H}=830 \mathrm{~m} \\
\end{array}$ & $\begin{array}{c}0.035 \\
0.918 \\
0.146 \text { to } 0.186 \\
0.877 \text { to } 1.449 \\
0.15 \text { to } 0.50 \\
0.155 \text { to } 0.294 \\
0.268 \text { to } 0.303 \\
0.27 \text { to } 3.19 \\
0.288 \text { to } 0.306 \\
0.397 \text { to } 3.704 \\
0.60 \text { to } 6.50 \\
0.63 \text { to } 0.74 \\
0.99 \text { to } 1.28 \\
1.67 \text { to } 2.21 \\
2.9 \\
3.81 \text { to } 18.2 \\
7.0 \\
11.3 \\
\end{array}$ & $\begin{array}{c}\text { Balkaya \& Kalkan (2003) } \\
\ldots \\
\text { Hong \& Hwang (2000) } \\
\ldots \\
\text { Chopra (2005) } \\
\text { Kuz. \& Was. (2006) } \\
\text { Chopra (2005) } \\
\text { Goel \& Chopra (1997) } \\
\text { Chopra (2005) } \\
\text { Todorovska et al. (2005) } \\
\text { Goel \& Chopra (1997) } \\
\text { Chopra (2005) } \\
\text { Crawford \& Ward (1964) } \\
\text { Chopra (2005) } \\
\ldots \\
\ldots \\
\text { FEMA (2006) } \\
\text { Baker (2010) } \\
\end{array}$ \\
\hline \multicolumn{4}{|c|}{ Slender Structures } \\
\hline $\begin{array}{c}\text { Anemometer Pole } \\
\text { Industrial Chimneys } \\
\ldots \\
\ldots \\
\ldots \\
\text { Antenna Pole } \\
\text { Urban Light Pole } \\
\end{array}$ & $\begin{array}{c}\text { Steel Tube, } H=10 \mathrm{~m} \\
\text { Steel Tube, } H=25 \mathrm{~m} \\
\text { Steel Tube, } H=30 \mathrm{~m} \\
\text { Steel Tube, } H=100 \mathrm{~m} \\
\text { RC, } H=250 \mathrm{~m} \\
\text { Steel Tube, } H=30 \mathrm{~m} \\
\text { Steel, } H=14 \mathrm{~m}\end{array}$ & $\begin{array}{c}0.4902 \\
0.775 \\
0.787 \\
2.058 \\
3.57 \\
0.92 \text { to } 1.09 \\
1.85 \\
\end{array}$ & $\begin{array}{c}\text { Repetto \& Solari (2010) } \\
\text { Repetto \& Solari (2002) } \\
\ldots \\
\ldots \\
\text { Chopra }(2005) \\
\text { Repetto \& Solari }(2010) \\
\text { Repetto \& Solari }(2004)\end{array}$ \\
\hline
\end{tabular}

\subsection{Dynamic Response Amplification for Tornado Wind Loads}

Eq. (9) defines that $T_{v}$ is proportional to $r_{c}$ and $T_{v}{ }^{*}$ while being inversely proportional to $\mathrm{U}_{\infty}$. The vortex load application period Tv is smallest when $\mathrm{r}_{\mathrm{c}} / \mathrm{U}_{\infty}$ is minimized $\left(\mathrm{r}_{\mathrm{c}, \min } / \mathrm{U}_{\infty, \max }=\right.$ $\left.46 \mathrm{~m} / 32.6 \mathrm{~m} \cdot \mathrm{s}^{-1}=1.41 \mathrm{~s}^{-1}\right)$ and largest when $\mathrm{r}_{\mathrm{c}} / \mathrm{U}_{\infty}$ is maximized $\left(\mathrm{r}_{\mathrm{c}, \max } / \mathrm{U}_{\infty, \min }=2008 \mathrm{~m} / 11.6 \mathrm{~m}\right.$ 
$\left.\cdot \mathrm{s}^{-1}=173.10 \mathrm{~s}^{-1}\right)$. Documented tornado-vortex parameters span a wide range, and any vortex load application period in the range $T_{\mathrm{v}, \text { min }}<\mathrm{T}_{\mathrm{v}}<\mathrm{T}_{\mathrm{v}, \max }$ is possible. Table 6 summarizes $\mathrm{T}_{\mathrm{v}, \text { min }}$ for each profile based upon the documented tornado vortex parameters in Table 4 and the definition of $T_{v}$ provided by Eq. (9).

Table 6: Minimum vortex loading period for each vortex profile.

\begin{tabular}{|c|cccc|}
\hline Profile & $\begin{array}{c}\mathrm{T}_{\mathrm{v}}{ }^{*} \\
(\operatorname{dim})\end{array}$ & $\begin{array}{c}\mathrm{r}_{\mathrm{c}, \min } \\
(\mathrm{m})\end{array}$ & $\begin{array}{c}\mathrm{U}_{\infty, \max } \\
(\mathrm{m} / \mathrm{s})\end{array}$ & $\begin{array}{c}\mathrm{T}_{\mathrm{v}, \min } \\
(\mathrm{s})\end{array}$ \\
\hline RCVM & 4.08 & 46.00 & 32.60 & 5.76 \\
L-O & 4.44 & $\ldots$ & $\ldots$ & 6.27 \\
S-K & 5.08 & $\ldots$ & $\ldots$ & 7.17 \\
\hline
\end{tabular}

The response of any structure for which $T_{n} \geq T_{v, \text { min }}$ can experience maximum dynamic amplification from tornado wind loads. Structures for which $T_{n}<T_{v, \text { min }}$ require that $\operatorname{DLF}\left(T_{v} / T_{n}\right)$ be defined using the DLF curves in Figures 20a-20c, where the ratio $T_{v} / T_{n}$ is computed using $T_{v}=T_{v, \text { min }}$. Figure 21a plots $\operatorname{DLF}\left(T_{n}\right)$ curves for each of the three vortex profiles (Recall that these three profiles represent the range of measured tornado-vortex profiles). Now a general DLF curve for tornado wind loading is defined by curve fitting the upper bound of the three DLF curves using the three region (R1-R3) envelope shown in Figure 21b. The three regions are: (R1) a linear region from $0<T_{n} \leq 2.90 \mathrm{~s}$, (R2) an exponential region from $2.90 \mathrm{~s}<\mathrm{T}_{\mathrm{n}}<7.25 \mathrm{~s}$, and (R3) a constant region for $T_{n} \geq 7.25 \mathrm{~s}$. The general tornado-vortex DLF curve is re-plotted in Figure 22a, and the equations for R1-R3 are provided.

Figure $22 \boldsymbol{b}$ illustrates where each of the four structure groups (G1-G4) defined previously in Section 6.1 fall allong the general tornado-vortex DLF curve. Typical wood frame structures (G1) will experience minimal dynamic amplification of tornado wind loads. However, tall concrete (G2) and steel (G4) structures as well as slender structures such as chimneys and poles (G3) may experience significant dynamic response amplification to tornado wind loads. 
The potential for dynamic response amplification to tornado wind loads is present and should be weighed in the construction of such structures.

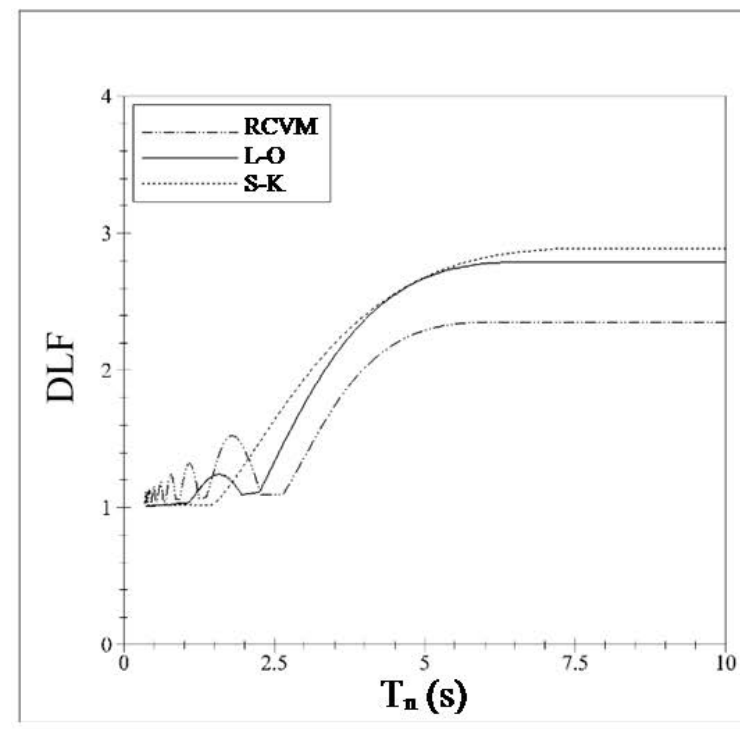

(a)

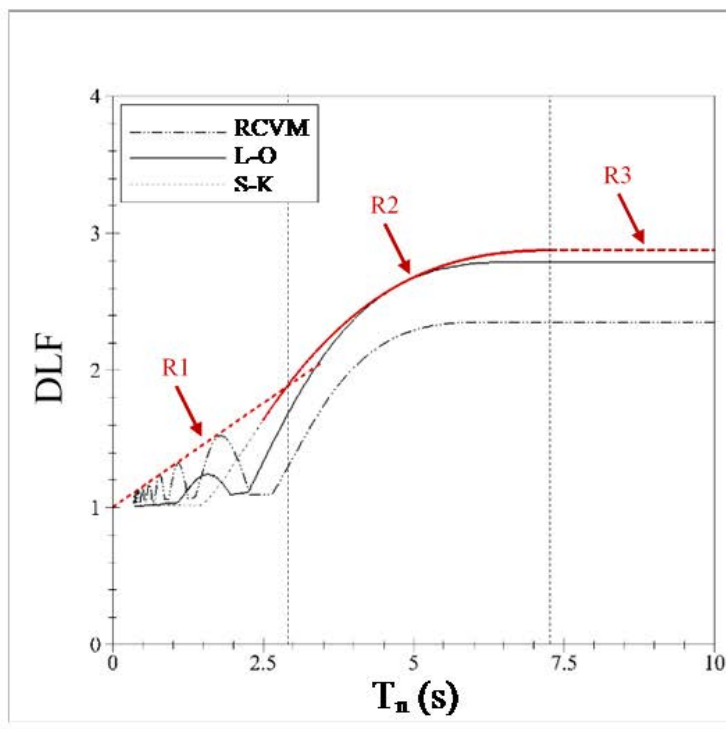

(b)

Figure 21: (a) $\operatorname{DLF}\left(T_{n}\right)$ curves for three vortex tangential velocity profiles and (b) 3-region, envelope defining the general tornado-vortex DLF curve.

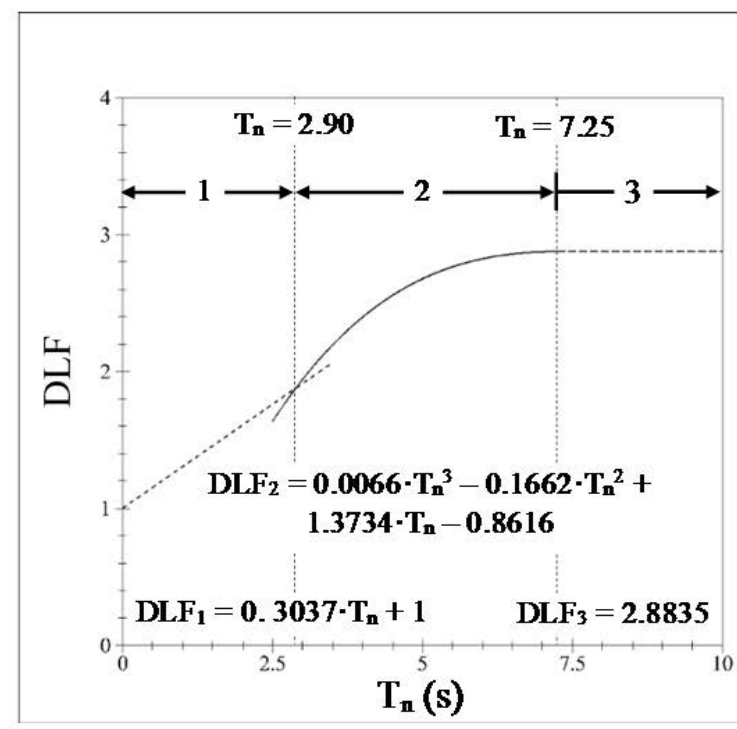

(a)

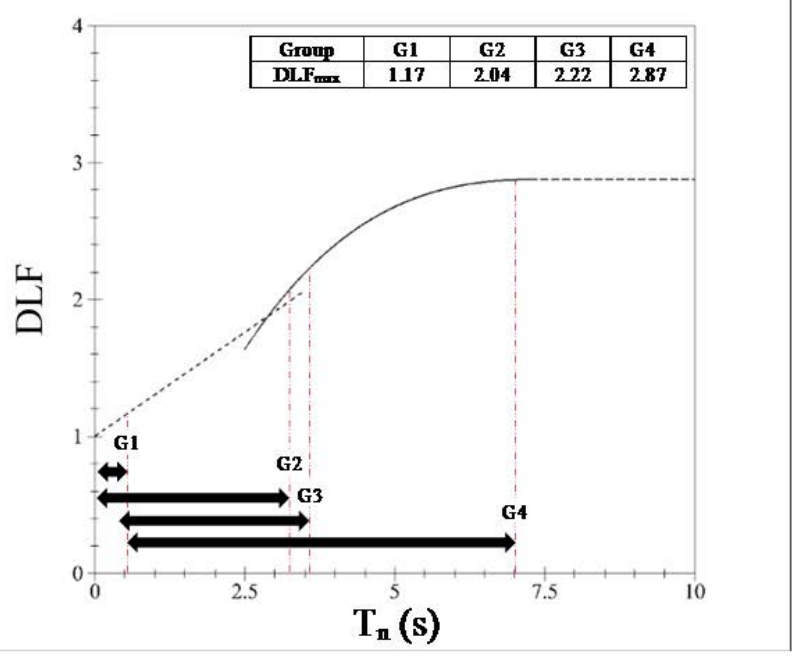

(b)

Figure 22: (a) Maximum dynamic amplification of tornado wind loading as function Tn and (b) illustration of maximum DLF values for structure groups G1-G4.

\subsection{Practical Assessment of Tornado Dynamic Loading Threat}


Figure 22a shows that the responses of structures having $\mathrm{T}_{\mathrm{n}} \geq 7.25 \mathrm{~s}$ to tornado wind loads may be dynamically amplified by up to 2.88 times. There are very few practical structures with $T_{n} \geq 7.25 \mathrm{~s}$; however, DLF values of 2.0 are possible for structures with $T_{n}$ as low as $3.10 \mathrm{~s}$, which is well within the practical fundamental frequency range for multi-story steel and concrete structures. Furthermore, the fact that tornado-like vortices have been shown to produce up to 1.5 times greater lateral wind loading than straight line wind ((Selvam \& Millet, 2005) and (Hann et al., 2010)) must also be considered. Computation of tornado wind loads for tall structures assuming the tornadic wind can be treated as straight-line wind could be quite erroneous as lateral tornado wind loadings may be in excess of $2.0 \cdot 1.5=3.0$ times greater than those produced by straight line winds (Here, 2.0 is the maximum probable DLF value for a practical structure and 1.5 is the increased loading factor for tornado versus straight-line wind loads).

In summary, dynamic amplification of tornado wind loading is a concern primarily for tall, flexible structures and requires that the tornado vortex be small and rapidly-translating. Small vortices orbiting rapidly within "multi-vortex" tornados have been documented (Lewellen et al., 2000) and may themselves have greater propensity to excite dynamic structure response. Finally, tornados with sharper tangential velocity profiles (Similar to RCVM) pose a greater dynamic loading threat than tornados with smooth profiles (Similar to S-K). This statement is not necessarily intuitive, as Figure 21 clearly shows that smoothe-profiled S-K vortex produce greater maximum dynamic amplification than the sharper RCVM. However, the S-K profile's DLF value only exceeds the RCVM profiles's DLF value for structures having $\mathrm{T}_{\mathrm{n}}>2.9 \mathrm{~s}$. Table 5 shows that this is beyond the fundamental period range of most practical structures, leading to the conclusion that sharper vortex profiles, such as the RCVM, pose greater dynamic loading threat than smoother profiles such as the S-K. 


\section{Summary and Conclusions}

The dynamic load factor (DLF) concept has been applied to define the first generalized assessment of the dynamic loading threat of tornado-like wind loads to real-world structures. Two-dimensional loading of a rigid, circular cylinder by an impinging vortex is directly simulated. The resulting cylinder loading is applied as forcing to a single degree of freedom (SDOF) response model, and the vortex load application period $\mathrm{T}_{\mathrm{v}}$ is defined as the frequency for which the dynamic amplification of the SDOF structure's response is greatest. Measured tornado-vortex tangential velocity profiles are compared with analytical vortex profiles, and three analytical profiles are selected: Rankine Combined (RCVM), Lamb-Oseen (L-O), and Scully-Kauffman (S-K), because they collectively represent the range of tornado-vortex tangential velocity profiles. DLF analysis is used to define $T_{v}$ as a function of the vortex's critical radius $r_{c}$, translational velocity $U_{\infty}$, and tangential velocity profile. Each vortex velocity profile produces a unique forcing profile, hence a unique DLF curve. DLF curves are defined for each of the vortex profiles using the definition of $\mathrm{T}_{\mathrm{v}}$. Documented tornado-vortex parameters are surveyed leading to the definitions of the core radii range of $46 \mathrm{~m} \leq \mathrm{r}_{\mathrm{c}} \leq 2008 \mathrm{~m}$ and translational velocity range of $11.60 \mathrm{~m} \cdot \mathrm{s}^{-1} \leq \mathrm{U}_{\infty} \leq 32.60 \mathrm{~m} \cdot \mathrm{s}^{-1}$. The possible DLF value of a structure having fundamental period $T_{n}$ due to tornadic wind loads is defined using the definition of $T_{v}$, the DLF curves for the three vortex velocity profiles, and the range of documented tornado-vortex parameters. Based upon the content of the present study, the conclusions discussed subsequently have been reached.

The load-application period of a vortex's tangential wind field " $\mathrm{T}_{\mathrm{v}}=\mathrm{T}_{\mathrm{v}}{ }^{*} \cdot \mathrm{r}_{\mathrm{c}} \cdot \mathrm{U}_{\infty}{ }^{-1}$ " is a function of three vortex parameters. The dimensionlss vortex loading period $\mathrm{T}_{\mathrm{v}}{ }^{*}$ introduces the influence of the vortex's tangential wind profile. The dimensionless vortex loading period $\mathrm{T}_{\mathrm{v}}{ }^{*}$, 
hence $\mathrm{T}_{\mathrm{v}}$, progressively increases as the vortex's tangential velocity profile flattens $\left(\mathrm{T}_{\mathrm{v}}{ }^{*}=4.08\right.$, 4.44, and 5.08 for RCVM, L-O, and S-K respectively).

Documented tornado-vortex parameters ranges $\left(46 \mathrm{~m} \leq \mathrm{r}_{\mathrm{c}} \leq 2008 \mathrm{~m}\right.$ and $11.60 \mathrm{~m} \cdot \mathrm{s}^{-1} \leq$ $\mathrm{U}_{\infty} \leq 32.60 \mathrm{~m} \cdot \mathrm{s}^{-1}$ ) are used along with the definition of $\mathrm{T}_{\mathrm{v}}$ and the DLF curves for the three vortex tangential velocity profiles to assess the dynamic loading threat posed by tornado vortices. A three-part, piecewise curve is developed and used to define the maximum dynamic amplification that a structure may experience as function of its fundamental period $T_{n}$.

1. $2.90 \mathrm{~s} \geq \mathrm{T}_{\mathrm{n}} \quad \rightarrow \mathrm{DLF}=0.3037 \cdot \mathrm{T}_{\mathrm{n}}+1$

2. $2.90 \mathrm{~s}<\mathrm{T}_{\mathrm{n}}<7.25 \mathrm{~s} \rightarrow \mathrm{DLF}=0.0066 \cdot \mathrm{T}_{\mathrm{n}}^{3}-0.1662 \cdot \mathrm{T}_{\mathrm{n}}^{2}+1.3734 \cdot \mathrm{T}_{\mathrm{n}}-0.8616$

3. $\quad \mathrm{T}_{\mathrm{n}} \geq 7.25 \mathrm{~s} \rightarrow \mathrm{DLF}=2.8835$

The definition of $T_{v}$ shows that a small, rapidly-translating tornado is required to produce dynamically-amplified loading of practical real-world structures. Consequently, typical woodframe residences $\left(T_{n} \leq 0.20 \mathrm{~s}\right)$ and other rigid structures do not bear significant threat for dynamic loading from tornados. However, tall, flexible structures may experience significant dynamic loading from tornado wind loads, and the potential dynamic load amplification should be considered for flexible structurs that are constructed in tornado-prone regions.

\section{Future Work}

The next phase of this study is to incorporate the three-dimensional aspect of vortex loading of a study using computer simulation. Recent studies show that interaction with a structure (Such as a large building) may significantly disrupt the vortex (Gorecki \& Selvam, 2015). The present study finds that small, rapidly-moving vortices are a dynamic threat primarily to tall steel and concrete structures. Such structures have a large footprint, so it is possible that they may disrupt the vortex, resulting in a very different force profile acting on the structure. 
This does not imply there will not be dynamic loading, but rather that the changed forcing profile may produce different dynamic loading. This topic shall be evaluated in subsequent studies.

\section{Acknowledgments}

The authors would like to acknowledge the National Science Foundation, the James T.

Womble Endowment, and the Schueck Family Fund for providing the financial resources under which this research was conducted at the University of Arkansas. The opinions expressed herein are solely those of the authors and do not reflect those of the funding parties.

\section{Works Cited}

Baker, 2010. The Burj Khalifa Triumphs: Engineering an Idea: The Realization of the Burj Khalifa, Civil Engineering-ASCE 80.3, 44-47.

Balkaya, C., \& Kalkan, E., 2003. Estimation of fundamental periods of shear-wall dominant building structures, Earthquake Engineering and Structural Dynamics 32, 985-998.

Bhagwat, M.J., \& Leishman, J.G., 2002. Generalized Viscous Vortex model for Application to Free-Vortex Wake and Aeroacoustic Calculations, Annual Forum Proceedings-American Helicopter Society 58.2, 2042-2057.

Bluestein, H.B., Lee, W-C., Bell, M., Weiss, C.C., \& Pazmany, A.L., 2003. Mobile Doppler Radar Observations of a Tornado in a Supercell near Bassett, Nebraska, on 5 June 1999. Part II: Tornado-Vortex Structure, Monthly Weather Review 131, 2968-2984.

Chopra, A.K., 2005. Dynamics of Structures: Theory and Application to Earthquake Engineering. Prentice Hall, Englewood Cliffs, NJ, USA.

Crawford, R., \& Ward, H.S., 1964. Determination of the Natural Periods of Buildings, Bulletin of the Seismological Society of America 54.6, 1743-1756.

Dukowicz, J., \& Ramshaw, J., 1979. Tensor viscosity method for convection in numerical fluid dynamics, J. Computational Physics 32.1, 71-79.

Dutta, P.K., Ghosh, A.K., \& Agarwal, B.L., 2002. Dynamic response of structures subjected to tornado loads by FEM. J. Wind Engineering and Industrial Aerodynamics 90, 55-69.

Edwards, R., \& Brooks, H.E., 2010. Possible Impacts of the Enhanced Fujita Scale on United States Tornado Data, Proc. $25^{\text {th }}$ Conf. on Severe Local Storms, Denver, CO. Available online at www.noaa.gov (Accessed: February 26, 2015). 
FEMA, 2006. Designing for Earthquakes (Chapter 4). Available Online: http://www.fema.gov/media-library-data/20130726-1556-204905679/fema454_complete.pdf (Accessed: 6-1-2015).

Fujita, T.T., 1981. Tornado Wind Effects on the Grand Gulf Cooling Tower, Proc. $2^{\text {nd }}$ Specialty Conference on Dynamic Response of Structures-Experimentation, Observation, Prediction, and Control, 555-566.

Fujita, T.T., 1976. Recent concept of tornado winds, in: Hatsuo Ishizaki, Arthur N.C. (Eds.), Proc. $2^{\text {nd }}$ USA-Japan Research Seminar on Wind Effects on Structures, University of Tokyo, Tokyo, Japan, 1-14.

Fujita, T.T., 1973. Tornadoes Around the World, Weatherwise 26.2, 56-83.

Giosan, I., \& Eng, P., 2013. Vortex shedding induced loads on free standing structures. Structural Vortex Shedding Response Estimation Methodology and Finite Element Simulation. Available Online: http://www.wceng-fea.com/vortex_shedding.pdf (Accessed: 7-8-2015).

Goel, R.K., \& Chopra, A.K., 1997. Period Formulas for Moment-Resisting Frame Buildings, J. Structural Engineering 123.11, 1454-1461.

Gorecki, P., \& Selvam, R.P., 2015. Rankine combined vortex interaction with a rectangular prism, IJ Computational Fluid Dynamics 29.1, 120-132.

Graf, W, 2008. The ShakeOut Scenario: Supplemental Study: Woodframe Buildings (USGS/CGS Report), colorado.edu. Available Online: http://www.colorado.edu/hazards/shakeout/woodframe.pdf (Accessed 6-1-2015).

Haan, F.L., Balaramudu, V.K., \& Sarkar, P.P., 2010. Tornado-Induced Wind Loads on a LowRise Building, J. Structural Engineering 136, 106-116.

Jischke, M.C., \& Light, B.D., 1983. Laboratory Simulation of Tornadic Wind Loads on a Rectangular Model Structure, J. Wind Engineering and Industrial Aerodynamics 13, 371382.

Haan, F.L., Balaramudu, V. K., \& Sarkar, P.P., 2010. Tornado-Induced Wind Loads on a LowRise Building, J. Structural Engineering 136, 106-116.

Hafeez, G., Doudak, G., \& McClure, G., 2014. Effect of Non-Structural Components on the Natural Period of Wood Light-Frame Buildings, Proc. World Conference on Timber Engineering. Available Online: http://newbuildscanada.ca/wpcontent/uploads/2010/11/wcte-2014_PAP084_Hafeez.pdf (Accessed: 6-22-2015). 
Hong, L-L., \& Hwang, W-L., 2000. Empirical formula for fundamental vibration periods of reinforced concrete buildings in Taiwan, Earthquake Engineering and Structural Dynamics 29, 327-337.

Kosiba, K., \& Wurman, J., 2010. The Three-Dimensional Axisymmetric Wind Field Structure of the Spencer, South Dakota, 1998 Tornado, J. Atmospheric Sciences 67, 3074-3083.

Kuai, L., Haan, F.L., Gallus, W.A., \& Sarkar, P.P., 2008. CFD simulations of the flow field of a laboratory-simulated tornado for parameter sensitivity studies and comparison with field measurements, J. Wind and Structures 11.2, 1-22.

Kuźniar, K., \& Waszczyszyn, Z., 2006. Neural Networks and Principal Component Analysis for Identification of Building Natural Periods, J. Computing in Civil Engineering 20, 431436.

Kuo, J.L., 1971. Axisymmetric Flows in the Boundary Layer of a Maintained Vortex, $J$. Atmospheric Sciences 28.1, 20-41.

Lewellen, D.C., Lewellen, W.S., \& Xia, J., 2000. The Influence of a Local Swirl Ratio on Tornado Intensification near the Surface, J. Atmospheric Science 57, 527-544.

Mehta, K.C., McDonald, J.R., Minor, J., 1976. Tornadic Loads on Structures, in: Hatsuo Ishizaki, Arthur, N.C. Chiu (Eds), Proc. $2^{\text {nd }}$ USA-Japan Research Seminar on Wind Effects on Structures, University of Tokyo, Tokyo Japan, pp. 15-25.

Mittal, S., 2005. Excitation of shear layer instability in flow past a cylinder at low Reynolds number, I.J. Numerical Methods in Fluids 49, 1147-1167.

NOAA, 2013a. The May 31-June 1, 2013 Tornado and Flash Flooding Event (Webpage). Available online: http://www.srh.noaa.gov/oun/?n=events-20130531 (Accessed: 10-22014).

NOAA, 2013b. The May 20, 2013 Newcastle-South OKC-Moore EF-5 Tornado (Webpage). Available online: http://www.srh.noaa.gov/oun/?n=events-20130520-ef5tornado (Accessed: 10-2-2014).

NWS, 2014. Natural Hazard Statistics. Available online: http://www.nws.noaa.gov/om/hazstats.shtml (Accessed: April 13, 2015).

NWS, 2012. Tornados and Hurricanes. Available online: http://www.prh.noaa.gov/cphc/pages/FAQ/Hurricanes_vs_tornadoes.php (Accessed: April 13, 2015).

Qu, L., Norberg, C., Davidson, L., Peng, S-H., \& Wang, F., 2013. Quantitative numerical analysis of flow past a circular cylinder at Reynolds number between 50 and 200, $J$. Fluids and Structures 39, 347-370. 
Paz, M., \& Leigh, W., 2004. Structural Dynamics: Theory and Computation $5^{\text {th }}$ ed. Kluwar Academic Publishers, Norwell, MA, USA.

Repetto, M.P., \& Solari, G., 2010. Wind-induced fatigue collapse of real slender structures, Engineering Structures 32, 3888-3898.

Repetto, M.P., \& Solari, G., 2004. Directional Wind-Induced Fatigue of Slender Vertical Structures, J. Structural Engineering 130, 1032-1040.

Repetto, M.P., \& Solari, G., 2002. Dynamic crosswind fatigue of slender vertical structures, J. Wind and Structures 5.6, 527-542.

Selvam, R.P., \& Millet, P.C., 2005. Large eddy simulation of the tornado-structure interaction to determine structural loadings, J. Wind and Structures 8.1, 49-60.

Selvam, R.P., 1998. Computational procedures in grid based computational bridge aerodynamics, in Bridge Aerodynamics, 327-336.

Selvam, R.P., 1997a. Computation of pressures on Texas Tech University building using large eddy simulation, J. Wind Engineering and Industrial Aerodynamics 67\&68, 647-657.

Selvam, R.P., 1997b. Finite element modelling of flow around a circular cylinder using LES, $J$. Wind Engineering and Industrial Aerodynamics 67\&68, 129-139.

Sengupta, A., Haan, F.L., Sarkar, P.P., \& Balaramudu, V., 2008. Transient loads on buildings in microburst and tornado winds, J. Wind Engineering and Industrial Aerodynamics 96, 2173-2187.

Seniwongse, M-S-N., 1977. Inelastic Response of Multistory Buildings to Tornadoes, PhD Dissertation, Texas Tech University Department of Civil Engineering, Lubbock, TX.

Strasser, M.N., \& Selvam, R.P., 2015. The Variation in the Maximum Loading of a Circular Cylinder Impacted by a 2D Vortex with Time of Impact. J. Fluids and Structures 58, 6678.

Tan, C-T., 1975. Inelastic Response of High-Rise Buildings to Tornadoes, Master's Thesis, Texas Tech University Department of Civil Engineering, Lubbock, TX.

Tanamachi, R.L., Bluestein, H.B., Lee, W-C., Bell, M., \& Pazmany, A., 2007. Ground-Based Velocity Track Display (GBVTD) Analysis of W-Band Doppler Radar Data in a Tornado near Stockton, Kansas, on 15 May 1999, Monthly Weather Review 135, 783-800.

Thompson, D.S., 2015. WoodWorks Design Example: Five-Story Wood-Frame Structure over Podium Slab (pgs. 21-26) Available Online: woodworks.org. http://www.woodworks.org/wp-content/uploads/5-over-1-Design-Example.pdf (Accessed 6-1-2015). 
Todorovska, M.I., Trifunac, M.D., Hao, T-Y., \& Rjoub, Y.A1., 2007. Building Periods for Use in Earthquake Resistant Design Codes - Earthquake Response Data Compilation and Analysis of Time and Amplitude Variations, Final Report, US Geological Survey External Response Program. Project No. 05HQGR027.

Vatistas, G.H., Kozel, V., \& Mih, W.C., 1991. A Simpler Model for Concentrated Vortices, Experiments in Fluids 11, 73-76.

Wen, Y.K., 1975. Dynamic Tornadic Wind Loads on Tall Buildings, J. Structural Division 101.1, 169-185.

Williamson, C.H.K., 1996. Vortex Dynamics in the Cylinder Wake, Annual Reviews in Fluid Mechanics 28, 477-539.

Wood, V.T., \& White, L.W., 2011. A New Parametric Model of Vortex Tangential-Wind Profiles: Development, Testing, and Verification. J. Atmospheric Sciences, 68, 990-1006.

Yang, Y., Sarkar, P., \& Hu, H., 2011. An experimental study of a high-rise building model in tornado-like winds, J. Fluids and Structures 27, 471-486.

\section{Figure Captions}

Figure 1: Loading of a structure by a tornado-like vortex.

Figure 2: DLF curves for (a) triangle wave and (b) sine wave forcing profiles.

Figure 3: (a) Sine wave forcing profile having application period $T_{d}$ and (b) vortex forcing profile having unknown application period $\mathrm{T}_{\mathrm{v}}$.

Figure 4: Schematic of the parallel loading of a rigid, circular cylinder by a vortex.

Figure 5: (a) Dimensionless, tornado-vortex tangential velocity profiles and (b) comparison with analytical tangential velocity profiles defined by Eq. (3).

Figure 6: Schematics of the (a) computational domain and (b) grid.

Figure 7: Vortex-cylinder schematic used to develop the transient velocity boundary condition.

Figure 8: Comparison of vortex tangential velocity profiles defined by Eq. (3) for (a) $r_{c}=2 \cdot D$ and (b) $r_{c}=3 \cdot D$ with extracted profiles from simulations of $(c) r_{c}=2 \cdot D$ and (d) $r_{c}=3 \cdot D$.

Figure 9: Time histories of the (a) lift force coefficient and (b) decomposed lift force coefficient from computer-simulated loading of a circular cylinder by a L-O vortex.

Figure 10: Free stream lift force coefficient (a) time history and (b) DLF curve. 
Figure 11: Vortex loading lift force coefficient (a) time history and (b) DLF curve.

Figure 12: (a) Lift force coefficient DLF curves and (b) zoomed view of $f_{v}$ illustrating the progressive decrease in $f_{v}$ with increasing $r_{c}$.

Figure 13: (a) Vortex loading period as function of vortex critical radius for $2 \leq r_{c} / D \leq 10$ and (b) dimensionless region of the L-O vortex's tangential velocity profile corresponding to $\mathrm{T}_{\mathrm{v}}$.

Figure 14: (a) Vortex loading period as function of vortex translational velocity and (b) collapse of vortex loading period curves using the definition of Eq. (9).

Figure 15: (a) Definition of $\mathrm{T}_{\mathrm{v}}\left(\mathrm{r}_{\mathrm{c}}\right)$ for the three vortex profiles and (b) dimensionless regions of the three vortex tangential velocity profiles corresponding to $\mathrm{T}_{\mathrm{v}}{ }^{*}$.

Figure 16: Schematic of forces on a cylinder due to (a) a free stream and (b) a stream incident from any direction.

Figure 17: Mean force coefficient $\mathrm{C}_{M}$ and harmonic force coefficient amplitude $\mathrm{C}_{\mathrm{H}}$ as function of resultant velocity of the incident stream.

Figure 18: Comparison of force coefficient time histories from computer simulation and defined by the emperical equations Eqs. (10-14): (a) $\mathrm{V}_{\theta, \max } / \mathrm{U}_{\infty}=1.0$ and (b) $\mathrm{V}_{\theta, \max } / \mathrm{U}_{\infty}=4.3$.

Figure 19: (1) Mean lift force coefficient time histories for (a-c) RCVM, L-O, and S-K vortices and (2) comparison of $\mathrm{T}_{\mathrm{v}}$ from DLF of equation-defined forcing (black dots) with Eq. (9) (dashed line).

Figure 20: DLF curves for vortex loading by vortices having (a) RCVM, (b) L-O, and (c) S-K tangential velocity profiles.

Figure 21: (a) $\operatorname{DLF}\left(\mathrm{T}_{\mathrm{n}}\right)$ curves for three vortex tangential velocity profiles and (b) 3-region, envelope defining the general tornado-vortex DLF curve.

Figure 22: (a) Maximum dynamic amplification of tornado wind loading as function $\mathrm{Tn}$ and (b) illustration of maximum DLF values for structure groups G1-G4.

\section{Tables}

Table 1: Analytical vortex tangential velocity profiles approximated using Eq. (3).

\begin{tabular}{|c|c|c|}
\hline Profile & Abbreviation & $\mathrm{n}$ \\
\hline Rankine Combined & RCVM & 100 \\
\hline Lamb-Oseen & L-O & 2 \\
\hline Scully-Kauffman & S-K & 1 \\
\hline
\end{tabular}


Table 2: Comparison of mean $\mathrm{Cd}$ and $\mathrm{St}$ attained in the present study with values reported by other computer simulation studies in the literature.

\begin{tabular}{|c|cc|cc|cc|}
\hline \multirow{2}{*}{ Re } & \multicolumn{2}{|c|}{ (Mittal, 2005) } & \multicolumn{2}{|c|}{ (Qu et al., 2013) } & \multicolumn{2}{c|}{ (Current) } \\
& $\mathrm{Cd}$ & $\mathrm{St}$ & $\mathrm{Cd}$ & $\mathrm{St}$ & $\mathrm{Cd}$ & $\mathrm{St}$ \\
\hline 100 & 1.322 & 0.1644 & 1.317 & 0.1649 & 1.332 & 0.1641 \\
150 & $\sim \sim \sim$ & $\sim \sim \sim$ & 1.301 & 0.1841 & 1.312 & 0.1817 \\
200 & 1.327 & 0.1947 & 1.316 & 0.1958 & 1.317 & 0.1930 \\
300 & 1.370 & 0.2077 & $\sim \sim \sim$ & $\sim \sim \sim$ & 1.346 & 0.2061 \\
\hline
\end{tabular}

Table 3: Percentage of $\mathrm{V}_{\theta, \max }$ transported for each vortex size and profile.

\begin{tabular}{|c|c|c|c|}
\hline \multirow{2}{*}{$r_{c}$} & \multicolumn{3}{|c|}{ Profile } \\
\cline { 2 - 4 } & RCVM & L-O & S-K \\
\hline $2 \cdot \mathrm{D}$ & $80 \%$ & $94 \%$ & $98 \%$ \\
$3 \cdot \mathrm{D}$ & $91 \%$ & $>99 \%$ & $>99 \%$ \\
\hline
\end{tabular}

Table 4: Real-world tornado vortex parameters.

\begin{tabular}{|c|c|c|c|}
\hline Parameter & Units & Minimum & Maximum \\
\hline $\mathrm{r}_{\mathrm{c}}$ & $\mathrm{m}$ & 46.0 (Fujita, 1981) & 2008.0 (NOAA, 2013a) \\
\hline $\mathrm{U}_{\infty}$ & $\mathrm{m} \cdot \mathrm{s}^{-1}$ & $11.6(\mathrm{NOAA}, 2013 \mathrm{~b})$ & 32.6 (Fujita, 1973) \\
\hline $\mathrm{T}_{\mathrm{V}}{ }^{*}$ & $\sim \sim \sim$ & 4.08 & 5.02 \\
\hline
\end{tabular}

Table 5: Fundamental periods for real-world structures.

\begin{tabular}{|c|c|c|c|}
\hline Structure & Description & $\mathrm{T}_{\mathrm{n}}(\mathrm{s})$ & Source \\
\hline \multicolumn{4}{|c|}{ Wood-Frame Structures } \\
\hline $\begin{array}{c}\text { "Typical" Single-Story Residence } \\
\ldots \\
\text { 4-Story Structure on CC Slab } \\
\ldots \\
\text { 5-Story Structure on CC Slab }\end{array}$ & $\begin{array}{c}\text { Undamaged } \\
\text { Damaged } \\
\text { Undamaged } \\
\text { Damaged } \\
\mathrm{H}=15.24 \mathrm{~m} \\
\end{array}$ & $\begin{array}{c}0.15 \text { to } 0.20 \\
<0.50 \\
0.233 \text { to } 0.250 \\
0.345 \text { to } 0.370 \\
0.40 \text { to } 0.55 \\
\end{array}$ & $\begin{array}{c}\text { Graf (2008) } \\
\ldots \\
\text { Hafeez et al. (2014) } \\
\ldots \\
\text { Thompson (2015) } \\
\end{array}$ \\
\hline \multicolumn{4}{|c|}{ Civil Structures \& Skyscrapers } \\
\hline $\begin{array}{c}\text { Shear Wall Structures } \\
\ldots\end{array}$ & $\begin{array}{l}\text { RC, }(12 \times 8 \times 5.6 \mathrm{~m}) \\
\text { RC, }(27 \times 24 \times 42 \mathrm{~m})\end{array}$ & $\begin{array}{l}0.035 \\
0.918\end{array}$ & $\begin{array}{c}\text { Balkaya \& Kalkan (2003) } \\
\text {... }\end{array}$ \\
\hline
\end{tabular}


Buildings with Load Bearing Walls \& Moment-Resisting Frames Nuclear Reactor Housing 13 Buildings with Load Bearing Walls Morrow Point Dam

37 Moment-Resisting Frame Structures PineFlat Dam

21 Buildings in LA, CA

53 Moment-Resisting Frame Structures Medical Center, Richmond CA

National Health/Welfare Building Alcoa Building Transamerica Building

Golden Gate Bridge Main Span 601 Lexington Ave. (Citigroup Cent.) Burj Khalifa
$\mathrm{RC},(71 \times 10.98 \times 8.45 \mathrm{~m})$

$\mathrm{RC},(51.64 \times 17 \times 77.1 \mathrm{~m})$

$\mathrm{RC}$, Dome-Roofed

$\mathrm{RC}, \mathrm{H}=15 \mathrm{~m}$

$\mathrm{RC}, \mathrm{H}=139 \mathrm{~m}$

$\mathrm{RC}, 9<\mathrm{H}<91 \mathrm{~m}$

$\mathrm{RC}, \mathrm{H}=122 \mathrm{~m}$

RC \& Steel, $20<\mathrm{H}<100 \mathrm{~m}$

Steel, $12.5<\mathrm{H}<257 \mathrm{~m}$

Steel, $\mathrm{H} \approx 10 \mathrm{~m}$

RC \& Steel, (43 x 27 x 72m)

Steel, $\mathrm{H}=120 \mathrm{~m}$

Steel, $\mathrm{H}=260 \mathrm{~m}$

$\mathrm{L}=1280 \mathrm{~m}$

RC \& Steel, $H=279 \mathrm{~m}$ $\mathrm{H}=830 \mathrm{~m}$
0.146 to 0.186

0.877 to 1.449

0.15 to 0.50

0.155 to 0.294

0.268 to 0.303

0.27 to 3.19

0.288 to 0.306

0.397 to 3.704

0.60 to 6.50

0.63 to 0.74

0.99 to 1.28

1.67 to 2.21

2.9

3.81 to 18.2

7.0

11.3
Hong \& Hwang (2000)

Chopra (2005)

Kuz. \& Was. (2006)

Chopra (2005)

Goel \& Chopra (1997)

Chopra (2005)

Todorovska et al. (2005)

Goel \& Chopra (1997)

Chopra (2005)

Crawford \& Ward (1964)

Chopra (2005)

...

FEMA (2006)

Baker (2010)

\section{Slender Structures}

Anemometer Pole

Industrial Chimneys

...

...

$\cdots$

Antenna Pole Urban Light Pole

Steel Tube, $\mathrm{H}=10 \mathrm{~m}$

Steel Tube, $\mathrm{H}=25 \mathrm{~m}$

Steel Tube, $\mathrm{H}=30 \mathrm{~m}$

Steel Tube, $\mathrm{H}=100 \mathrm{~m}$

$$
\mathrm{RC}, \mathrm{H}=250 \mathrm{~m}
$$

Steel Tube, $\mathrm{H}=30 \mathrm{~m}$

Steel, $\mathrm{H}=14 \mathrm{~m}$

$\begin{array}{cc}0.4902 & \text { Repetto \& Solari (2010) } \\ 0.775 & \text { Repetto \& Solari (2002) } \\ 0.787 & \ldots \\ 2.058 & \ldots \\ 3.57 & \text { Chopra (2005) } \\ .92 \text { to } 1.09 & \text { Repetto \& Solari (2010) } \\ 1.85 & \text { Repetto \& Solari (2004) }\end{array}$

Table 6: Minimum vortex loading period for each vortex profile.

\begin{tabular}{|c|cccc|}
\hline Profile & $\begin{array}{c}\mathrm{T}_{\mathrm{v}}{ }^{*} \\
(\mathrm{dim})\end{array}$ & $\begin{array}{c}\mathrm{r}_{\mathrm{c}, \min } \\
(\mathrm{m})\end{array}$ & $\begin{array}{c}\mathrm{U}_{\infty, \max } \\
(\mathrm{m} / \mathrm{s})\end{array}$ & $\begin{array}{c}\mathrm{T}_{\mathrm{v}, \min } \\
(\mathrm{s})\end{array}$ \\
\hline RCVM & 4.08 & 46.00 & 32.60 & 5.76 \\
L-O & 4.44 & $\ldots$ & $\ldots$ & 6.27 \\
S-K & 5.08 & $\ldots$ & $\ldots$ & 7.17 \\
\hline
\end{tabular}

